\title{
An Objective Method for Computing Advective Surface Velocities From Sequential Infrared Satellite Images
}

\author{
W. J. Emery, ${ }^{1}$ A. C. Thomas, and M. J. Collins \\ Department of Oceanography, University of British Columbia, Vancouver, Canada \\ W. R. Crawford and D. L. Mackas \\ Institute of Ocean Sciences Sidney, British Columbia, Canada
}

\begin{abstract}
Using cross correlations between sequential infrared satellite images, an objective technique is developed to compute advective sea surface velocities. Cross correlations are computed in $32 \times 32$ pixel search (second image) and $22 \times 22$ template (first image) windows from gradients of sea surface temperature computed from the satellite images. Velocity vectors, computed from sequential images of the British Columbia coastal ocean, generally appear coherent and consistent with the seasonal surface current in the region. During periods of strong wind forcing, as indicated by maps of sea level pressure, the image advective velocities are stronger and more coherent spatially and appear to cross surface temperature gradients; when winds are weaker, the advective velocities correspond better with the infrared temperature patterns, suggesting the increased contribution of the geostrophic current to the surface flow. Velocities determined from coincident, near-surface drogued $(5-10 \mathrm{~m})$ buoys, positioned every half hour by internal LORAN-C units in mid-June, show excellent agreement with the image advective velocities. In addition, conductivity, temperature, and depth (CTD) measurements (taken during the buoy tracking) confirm the homogeneity of the upper $10 \mathrm{~m}$, and CTD-derived geostrophic currents are consistent with both buoy and sequential image displacement velocities.
\end{abstract}

\section{INTRODUCTION}

Recently, there has been increasing interest in computing surface velocities directly from high-resolution satellite images of infrared sea surface temperature (SST) patterns. The patterns have been shown to be consistent with current estimates from Lagrangian drifters [Kelly, 1985] and are thought to reflect near-surface ocean circulation. Another comparison between infrared image-derived surface velocities was reported by Kelly [1983], who used an analysis procedure based on an analytical model that inferred velocities from a single infrared image. Comparisons between these "geostrophic" currents, designed to match the satellite infrared SST gradients, and coincident Doppler acoustic log velocities, from the California Current region, showed good agreement.

Using sequential infrared images, La Violette [1984] estimated velocities around the Alboran Sea gyre. Vastano and Borders [1984] used a similar technique, with an interactive display system, to track submesoscale features in sequential infrared satellite images from the western North Pacific. Called feature tracking, this subjective, interactive technique was expanded on by Vastano and Reid [1985] who used the resulting surface velocity vectors to derive a two-dimensional stream function expression for the advective surface velocity field. Invoking geostrophy, they further infer a sea surface topography to match the stream function derived from the satellite image velocity vectors. The resultant "dynamic topography" estimate provides a high spatial resolution, satellitesynoptic estimate of the sea surface elevation which in the

\footnotetext{
${ }^{1}$ Now at National Center for Atmospheric Research, Boulder, Colorado.

Copyright 1986 by the American Geophysical Union.

Paper number 6C0434.

$0148-0227 / 86 / 006 C-0434 \$ 05.00$
}

future can be compared with surface topographies measured with satellite altimeters.

A basic weakness of the feature-tracking procedure is the need for subjective selection and tracking of SST features in the infrared satellite images. Such subjective feature tracking is necessarily operator dependent and cannot be recreated exactly by different operators of different display systems even using the same satellite images. It would be useful if a computational procedure existed that was objective and operator independent to compute surface advective velocities from sequences of satellite images. In this paper we apply a computational technique which has been widely used in satellite image registration [McGillem and Svedlow, 1977, 1978; Svedlow et al., 1978] and has also been used to detect cloud motion in sequential images [Leese et al., 1971]. In the image registration application, time invariant land features are located, while in the cloud tracking technique the displacements of cloud image features are calculated. This same procedure was recently applied to sequential visible satellite images of the eastern Beaufort Sea to compute ice displacements [Ninnis et al., 1986].

The essence of the computational method is the identifcation of the maximum cross correlation, between $32 \times 32$ search (second image) and $22 \times 22$ pixel template (first image) windows, as the end points of displacement vectors from the window centers. Applied directly to the satellite infrared temperatures, the weak cross-correlation maxima yielded incoherent velocity patterns. The satellite images were then transformed into maps of SST gradient and the maximum cross correlation (MCC) technique was applied to these gradient images. The resulting vectors were generally spatially coherent. In addition, for a sequence of three images in mid-June 1985, tracks of shallow-drogued drifters exhibit excellent agreement with the computed image advective velocities. Further supporting evidence was found in a coincident conduc- 
TABLE 1. Infrared Satellite Images

\begin{tabular}{cccrc}
\hline Date & $\begin{array}{c}\text { Local } \\
\text { Time }\end{array}$ & Satellite & Orbit & $\begin{array}{c}\text { Separation, } \\
\text { hours }\end{array}$ \\
\hline June 16 & 1258 & NOAA 9 & 2,630 & $\ldots$ \\
June 17 & 0257 & NOAA 9 & 2,638 & 14 \\
June 18 & 0246 & NOAA 9 & 2,652 & 24 \\
July 26 & 0811 & NOAA 8 & 12,008 & $\ldots$ \\
July 26 & 1937 & NOAA 8 & 12,105 & 12 \\
July 28 & 1353 & NOAA 9 & 3,223 & $\ldots$ \\
July 28 & 1854 & NOAA 8 & 12,133 & 5 \\
Aug. 12 & 1435 & NOAA 9 & 3,435 & $\ldots$ \\
Aug. 12 & 1829 & NOAA 8 & 12,346 & 4 \\
Aug. 15 & 1403 & NOAA 9 & 3,477 & $\ldots$ \\
Aug. 15 & 1904 & NOAA 8 & 12,389 & 5 \\
Aug. 16 & 1354 & NOAA 9 & 3,491 & 19 \\
Aug. 16 & 1842 & NOAA 8 & 12,403 & 5 \\
\hline
\end{tabular}

tivity, temperature, and depth (CTD) survey which revealed the homogeneity of the upper $(<10 \mathrm{~m})$ layer and yielded dynamic height contours consistent with both the drifting buoy and satellite image advective velocities.

In what follows we describe the methodology used to compute the SST gradients and the advective surface velocities. These methods are then applied to a series of satellite images of the British Columbia coastal ocean for the summer of 1985. Unusually clear atmospheric conditions made it possible to collect a large number of clear images at the University of British Columbia (UBC) Satellite Oceanography Laboratory. Image pairs selected for study range in separation from 4 to 24 hours (Table 1) and are discussed individually in terms of the short-term changes in SST patterns. During the latter half of June a field program of the Institute of Ocean Sciences in Sidney, British Columbia, collected half-hourly LORAN posi-
TABLE 2. Drifter Start and End Dates and Times and Deployment Positions

\begin{tabular}{|c|c|c|c|c|c|}
\hline \multirow[b]{2}{*}{ Buoy } & \multicolumn{2}{|c|}{ Start } & \multirow[b]{2}{*}{$\begin{array}{c}\text { Deployment } \\
\text { Position }\end{array}$} & \multicolumn{2}{|c|}{ End } \\
\hline & Date & $\begin{array}{l}\text { Time, } \\
\text { PST }\end{array}$ & & Date & $\begin{array}{l}\text { Time, } \\
\text { PST }\end{array}$ \\
\hline 2 & June 15 & 2036 & $\begin{array}{l}48^{\circ} 18^{\prime} 49^{\prime \prime} \mathrm{N} \\
125^{\circ} 31^{\prime} 01^{\prime \prime} \mathrm{W}\end{array}$ & June 18 & 1036 \\
\hline 2 & June 18 & 1438 & $\begin{array}{l}48^{\circ} 28^{\prime} 51^{\prime \prime} \mathrm{N} \\
125^{\circ} 15^{\prime} 07^{\prime \prime} \mathrm{W}\end{array}$ & June 19 & 1938 \\
\hline 2 & June 13 & 1232 & $\begin{array}{l}48^{\circ} 29^{\prime} 02^{\prime \prime} \mathrm{N} \\
125^{\circ} 15^{\prime} 25^{\prime \prime} \mathrm{W}\end{array}$ & June 14 & 2132 \\
\hline 4 & June 9 & 1144 & $\begin{array}{l}48^{\circ} 29^{\prime} 03^{\prime \prime} \mathrm{N}, \\
125^{\circ} 15^{\prime} 34^{\prime \prime} \mathrm{W}\end{array}$ & June 16 & 1814 \\
\hline 4 & June 17 & 1934 & $\begin{array}{l}48^{\circ} 21^{\prime} 02^{\prime \prime} \mathrm{N} \\
\quad 125^{\circ} 14^{\prime} 27^{\prime \prime} \mathrm{W}\end{array}$ & June 19 & 1104 \\
\hline 5 & June 9 & 1451 & $\begin{array}{l}48^{\circ} 26^{\prime} 10^{\prime \prime} \mathrm{N} \\
\quad 125^{\circ} 11^{\prime} 17^{\prime \prime} \mathrm{W}\end{array}$ & June 16 & 0600 \\
\hline 5 & June 17 & 1935 & $\begin{array}{l}48^{\circ} 21^{\prime} 05^{\prime \prime} \mathrm{N} \\
125^{\circ} 14^{\prime} 11^{\prime \prime} \mathrm{W}\end{array}$ & June 19 & 1635 \\
\hline 7 & June 9 & 1640 & $\begin{array}{l}48^{\circ} 23^{\prime} 47^{\prime \prime} \mathrm{N} \\
\quad 125^{\circ} 20^{\prime} 32^{\prime \prime} \mathrm{W}\end{array}$ & June 18 & 0640 \\
\hline 4 & June 24 & 1149 & $\begin{array}{l}48^{\circ} 26^{\prime} 18^{\prime \prime} \mathrm{N}, \\
125^{\circ} 20^{\prime} 12^{\prime \prime} \mathrm{W}\end{array}$ & June 26 & 2149 \\
\hline
\end{tabular}

tions of a group of four near-surface drogued drifters in addition to a set of CTD profiles in the vicinity of a cyclonic eddy over the shallow continental shelf off southwest Vancouver Island. Both of these additional data sources are shown to agree well with the image-derived surface velocities. We conclude with a summary of our results.

\section{Data}

The primary data source for this study was satellite imagery from polar-orbiting weather satellites (NOAA 8 and NOAA 9). The digital image data were all received and processed at

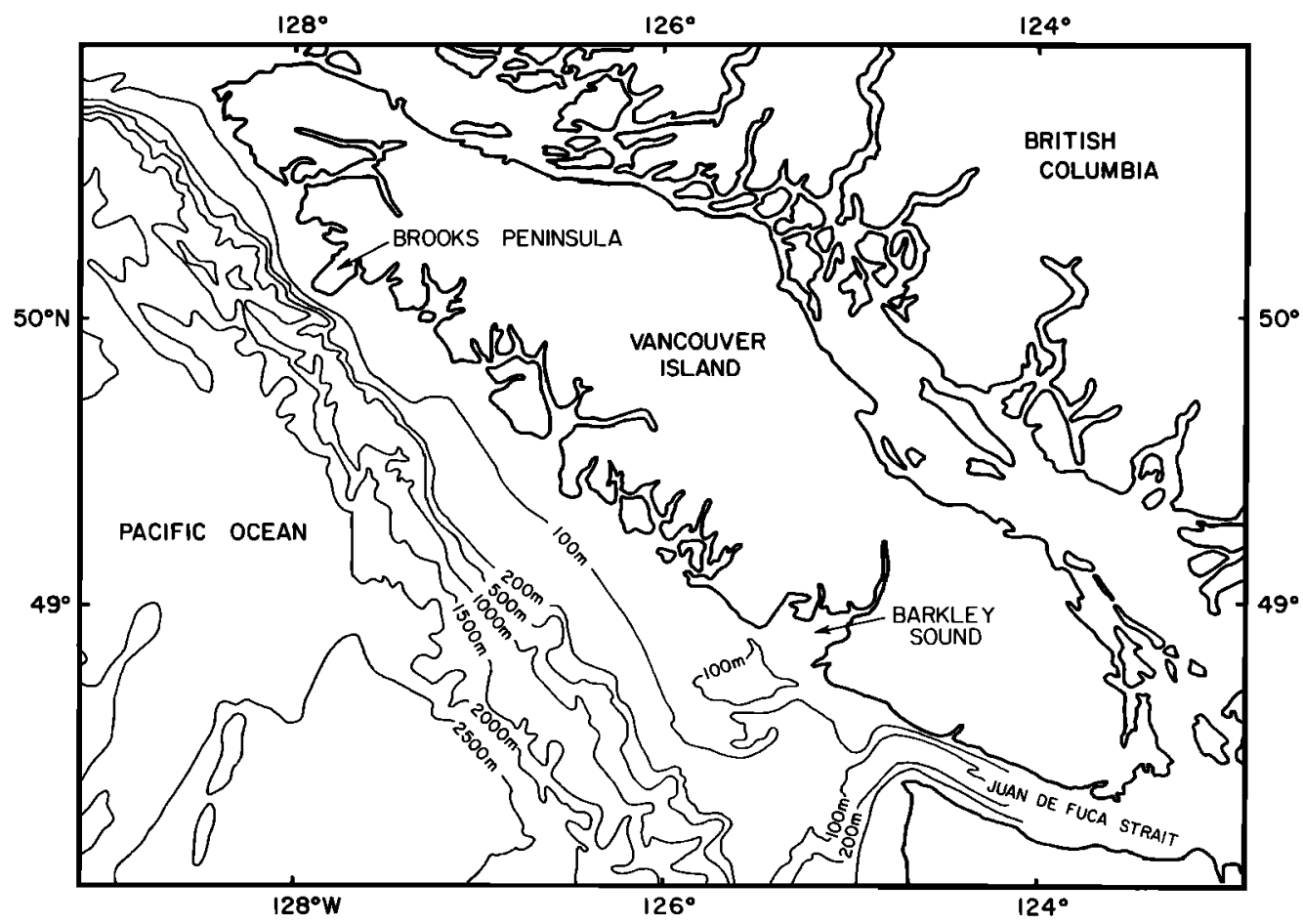

Fig. 1. Map of the study area. 


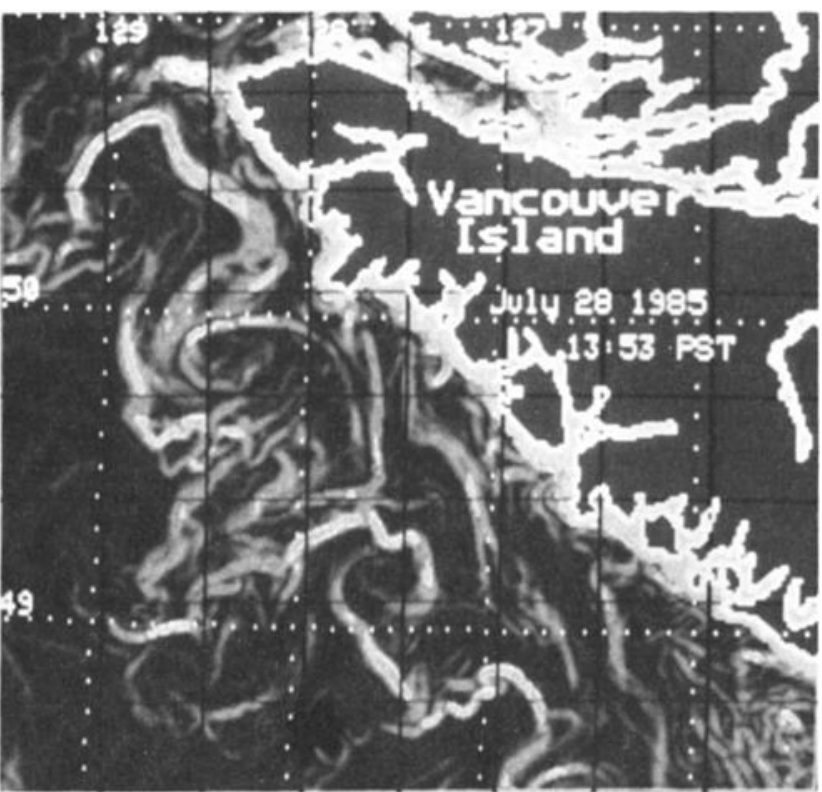

Fig. 2a

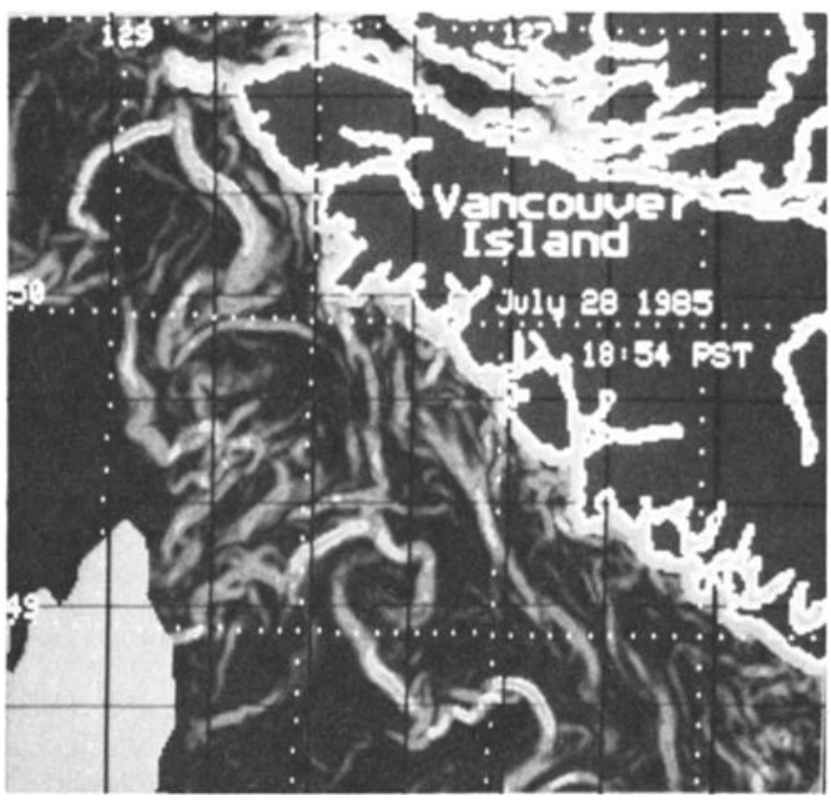

Fig. $2 b$

Fig. 2. Surface temperature gradient images computed from band 4 infrared AVHRR images for (a) 1353 PST July 28, 1985 , and (b) 1854 July 28, 1985. Strongest gradients are represented by the lightest shades while weakest gradients correspond to the darkest areas. The square grid of black lines represent the $32 \times 32$ pixel search windows of the MCC method.

the UBC Satellite Oceanography Laboratory. The summer 1985 images used to compute the advective velocities are listed in Table 1 . These images were selected by visual inspection as those containing a minimum of cloud cover. All clouds in these images were identified by a comparison between the visible (band 1) and infrared (band 4) images and were masked as uniform gray in the images. The shorter time intervals between images in Table 1 were made possible by the existence of two satellites; with a single satellite the shortest possible time interval is about 12 hours. An exception to this is when the orbit of a single satellite is such that the coast of British Columbia is seen by the same satellite on successive passes owing to high-latitude overlap. The resulting time interval between overlapping passes is 1.5 hours, but no such closely spaced images were available for this study.

All satellite images were navigated (corrected for distortion and registered to a map) to within $\pm 1 \mathrm{~km}$ (1 pixel) using satellite ephemeris data [Emery and Ikeda, 1984] and were nudged (entire image shifted to fit map overlay) to correct for receiving system timing errors. Comparisons between images navigated with this procedure and images navigated using a relatively large number $(>12)$ of coastal ground control points (GCPs) confirmed the stated accuracy (about $1 \mathrm{~km}$ ) of the ephemeris navigation procedure. Coastal land boundaries were added from a digital map, and all land areas were masked with a uniform brightness.

Band $4(11.5-12.5 \mu \mathrm{m})$ infrared images were converted to temperature using the single-channel reference temperatures. Since in this study, relative SST patterns (gradients), rather than absolute SST, were important, no correction was made for atmospheric water vapor contamination of the singlechannel infrared temperature. While water vapor not apparent in the visible or infrared channels can significantly alter the satellite-derived absolute SST [Bernstein and Chelton, 1985], it is unlikely that the spatial structure of the atmospheric boundary layer will significantly influence the much smaller spatial gradients of SST in the $32 \times 32 \mathrm{~km}$ correlation windows. Generally, the spatial scales of the atmospheric moisture structure are much greater than those of the SST features.

Coincident with the satellite images in June 1985 (Table 1) a set of shallow-drogued $(5-10 \mathrm{~m})$ buoys were tracked by shipbased LORAN off the southwest coast of British Columbia. These buoys were deployed, tracked by ship, recovered, and then redeployed to gather repeated trajectories in the area off the mouth of Juan de Fuca Strait (Figure 1). These trajectories, buoy numbers, dates, times, and positions of deployment are summarized here in Table 2 . Some of these trajectories were too short to be useful for our comparison purposes and do not show up in later diagrams. As part of this summer 1985 field study, a survey of shallow CTD profiles was collected in the same area that the buoys were deployed in.

\section{METHOD}

As was mentioned in the introduction, a first attempt at calculating velocities directly from the SST images was unsuccessful regardless of the image pair used. The lack of success was apparent by the relatively low maximum correlation values and the incoherent spatial structure of the resulting velocity fields. In an effort to produce SST features which the MCC algorithm could clearly identify, gradients of infrared SST were computed for all of the images in Table 1. It was shown by Svedlow et al. [1978] that using the magnitudes of the image gradients yielded better image registration results than were obtained when the cross-correlation method was applied to the images themselves. 


\section{MEAN AUTO-CORRELATION SURFACE DERIVED FROM SST-GRADIENT IMAGES}

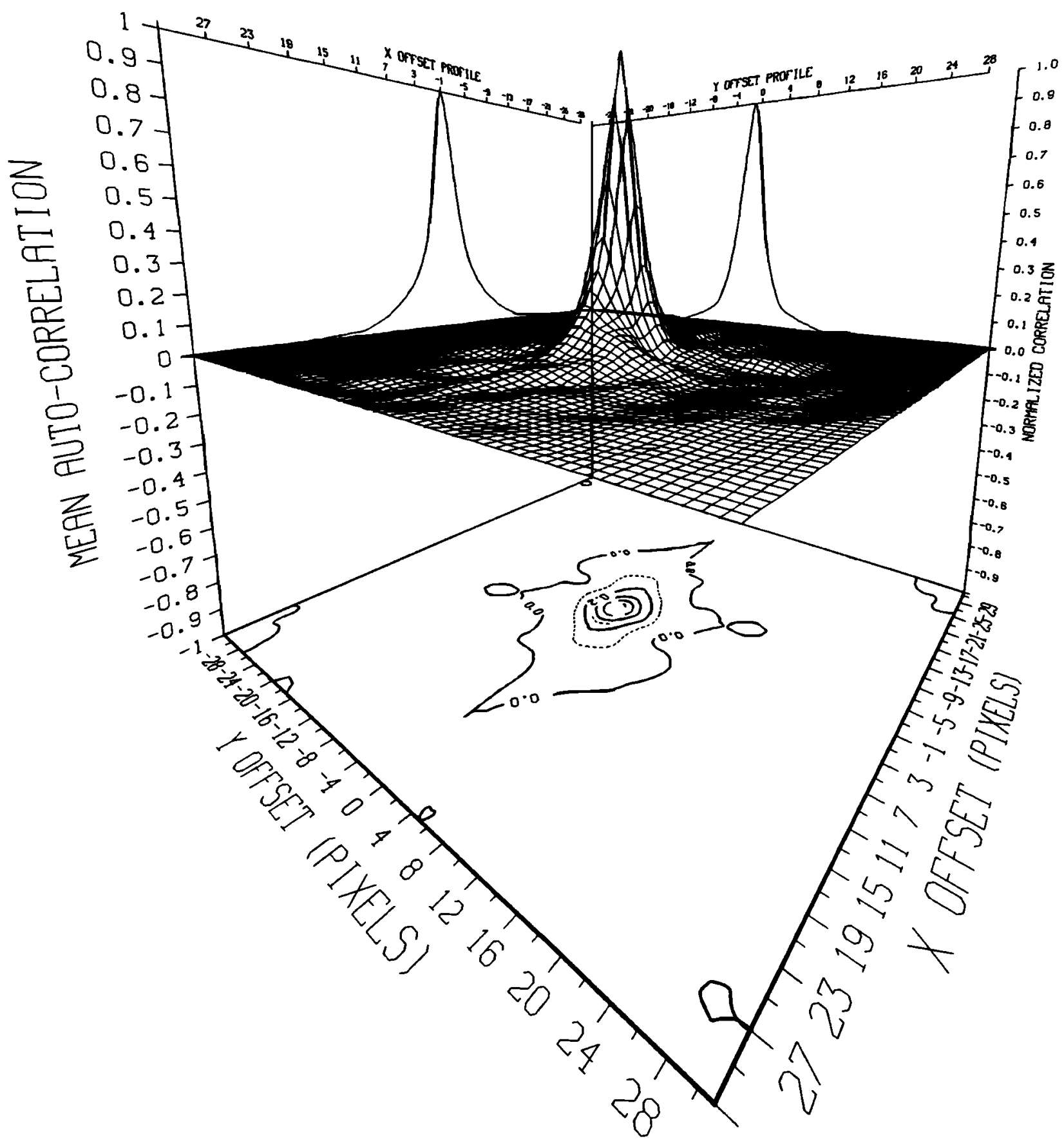

Fig. 3. Mean autocorrelation surface for all the template windows in Figure $2 a$. The $x$ and $y$ scales are in units of pixels which are approximately $1 \mathrm{~km}$ each.

Sea surface thermal features were first smoothed and small scale image noise was reduced using a $3 \times 3$ pixel running mean filter. Temperature gradients were then computed using an unweighted central difference, the magnitude of which is given by

$$
\begin{aligned}
|T(x, y)|=1 /(2 \Delta h)\left\{[T(x-\Delta h, y)-T(x+\Delta h, y)]^{2}\right. \\
\left.+[T(x, y-\Delta h)-T(x, y+\Delta h)]^{2}\right\}^{1 / 2}
\end{aligned}
$$

where the resulting temperature gradients are in units of degrees Celsius per kilometer [Van Woert, 1982]. Two kinds of temperature gradient images were produced: one was the straight SST gradient as computed in (1); for the second type of gradient the magnitude in (1) was limited to a selected threshold value producing a step function form of the SST gradient. This was an effort to best approximate those features seen by Ninnis et al. [1986] in visible ice images. In their 


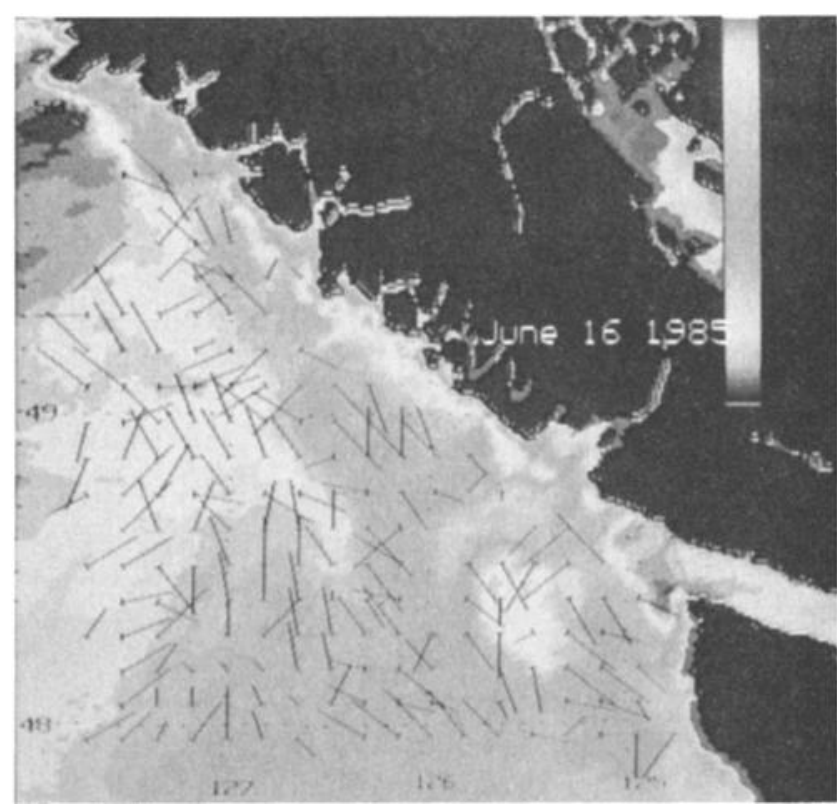

Plate $1 a$

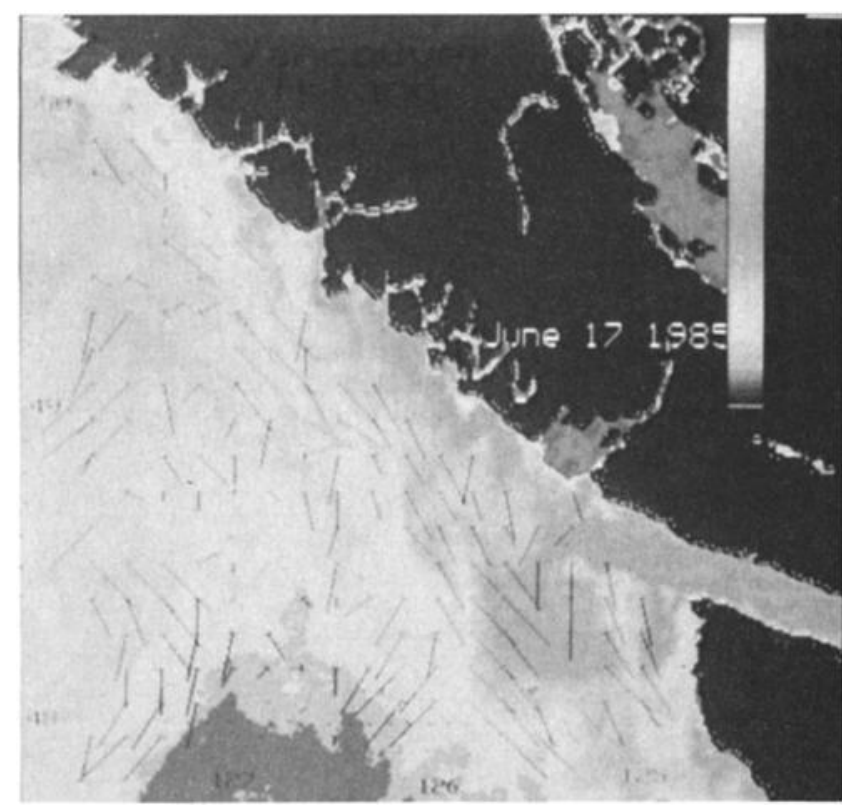

Plate $1 b$

Plate 1. Band 4 infrared AVHRR images with superimposed advective surface velocities for (a) 1208 PST June 16, 1985, with velocities for the June 16-17 image pair and (b) 0257 PST June 17, 1985, with velocities for the June 17-18 image pair. (The color version of this figure can be found in the separate color section in this issue.)

image registration application, Svedlow et al. [1978] also used threshold image gradients (thus producing a two-level binary image) and found that the image registration results from the MCC method were better than those using the original images but were not as good as the results using the image gradient itself. When applied to these two different types of SST gradients, the cross-correlation technique produced very similar results, and it was thus decided to use the simpler form of the SST gradient given by (1).

As examples of these SST gradient images we present two images from July 28,1985 , in Figures $2 a$ and $2 b$. Here the

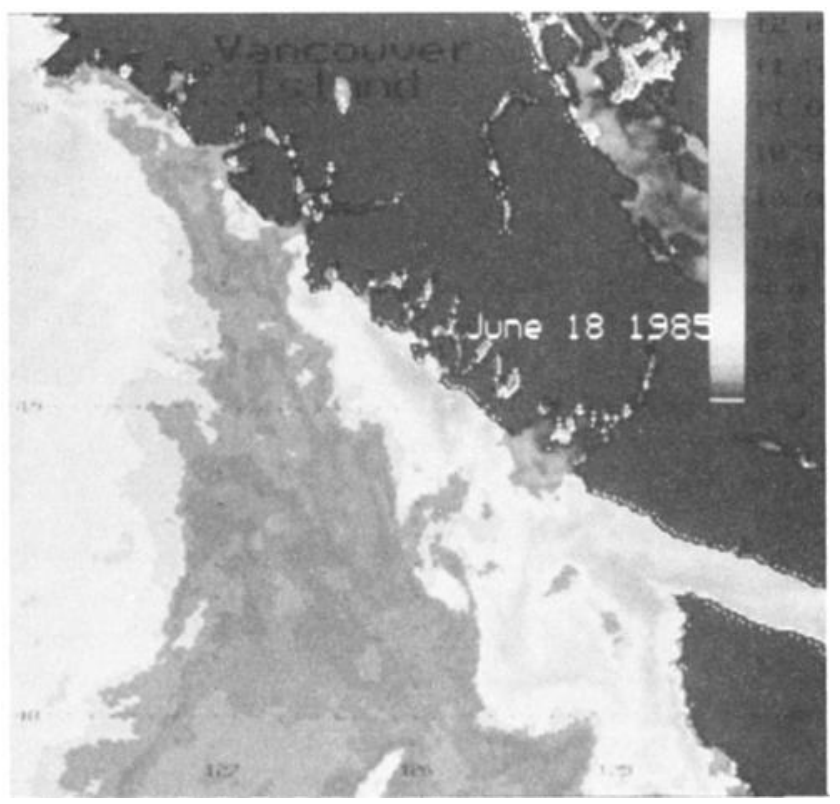

Fig. 4. Band 4 infrared AVHRR image with superimposed advective surface velocity for 0246 PST June 18, 1985. gradients have been enhanced so that strongest gradients are indicated by the lightest shades with the weakest gradients given by the darkest background shades. The images are separated in time by 5 hours and provide an example of the features followed by the MCC method. To facilitate the interpretation of these gradient images, we have added to the usual latitude-longitude grid a uniform grid of $32 \times 32$ pixel squares corresponding to the search windows in the MCC method.

In this computational procedure each infrared temperature gradient image is considered as being an independent realization of the SST, whose variations over relatively short time intervals are due only to surface advection. Thus the MCC in the two-dimensional lagged window specifies the end position of an advective surface velocity from the center of the window. A grid of windows provides a map of advective surface velocities. This method yields no information about the driving forces for these advective velocities and they contain both geostrophic and wind-driven surface currents. Advective velocities were in some cases clearly wind driven (appearing to have no relation to the surface temperature pattern), while in other cases the velocities were related to the surface thermal structure and the flow was along the stronger SST gradients.

An important limitation of the method, as presently applied, is its inability to account for SST gradient changes due to nonadvective mechanisms such as spatially patchy solar heating and surface cooling. No independent data were available to estimate the importance of these effects, but changes in SST patterns often suggested that advective velocities represented heating events. Away from the coastal boundaries, where freshwater discharge sharply affects the density currents, the SST advective velocities are more likely to be representative. Also, near coastal boundaries there is the problem that some windows will contain land and will not be consistent representations of the advective SST changes; all such velocities were edited out of the final advective fields.

No independent feature tracking was carried out to verify the MCC velocities as was done in the ice motion study of 


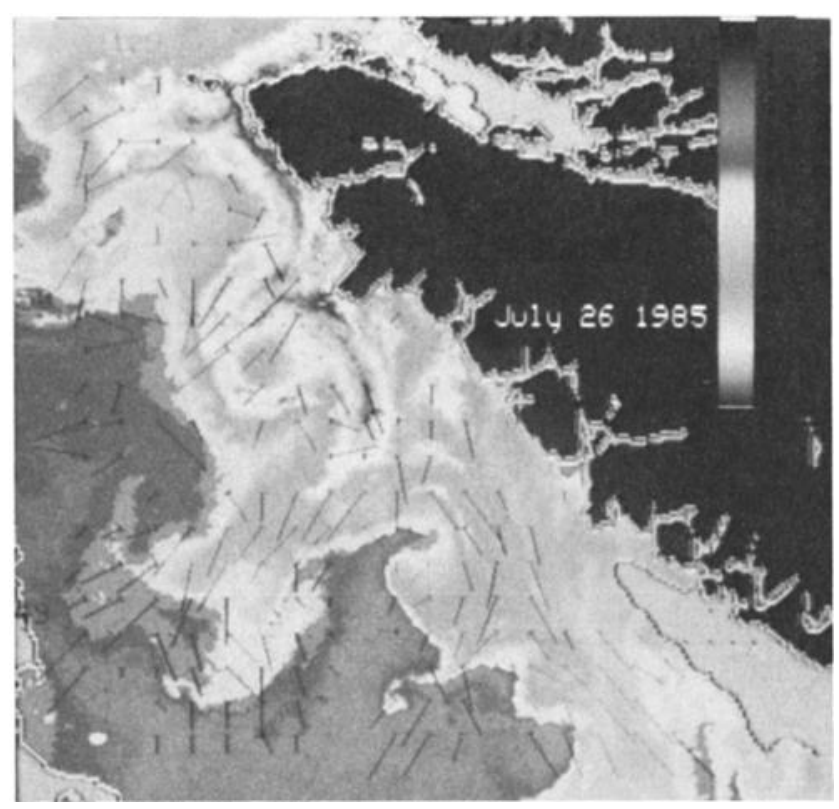

Plate $2 a$

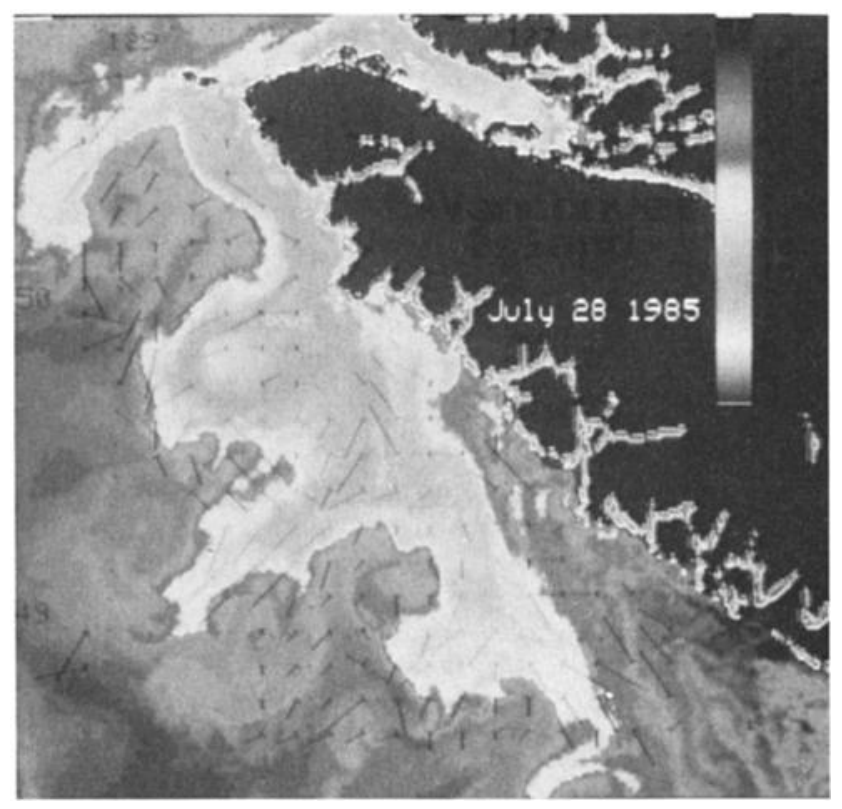

Plate $2 b$

Plate 2. Band 4 infrared AVHRR images with superimposed advective surface velocities for (a) 0811 July 26 , 1985 , with velocities for a pair of July 26 images at 0811 and 1937 (PST) and (b) 1353 July 28, 1985, with velocities for a pair of July 28 images at 1353 and 1854 PST.

Ninnis et al. [1986]. Instead, comparisons with the drifter trajectories and CTD dynamic heights were used to verify the velocity results of the MCC procedure. One important difference between the MCC and feature-tracking methods is the fact that the MCC method cannot respond to rotational or deformational changes while the subjective feature-tracking technique can. It should be noted, however, that for the very short time intervals between some image pairs (4-5 hours), small segments of rotational motion will appear as translation, which accounts for the good representation of the large-scale eddy motion clearly marked by the SST patterns in some of the summer images. It is likely that for longer image separations (12-24 hours) the MCC velocity vectors will less faithfully represent rotational motions.

A final comment should be made about the inability of the method to detect motion along surface temperature fronts. When such fronts are associated with underlying geostrophic currents, these currents should run along gradients of SST and thus not be reflected in the MCC advective velocities. It should be noted, however, that often the SST gradients are not narrowly defined and frequently have smaller-scale cross gradient structures that undergo displacements along the temperature gradient that will be detected by the MCC method. It is the motion of these smaller temperature filaments that leads to MCC velocities parallel to surface temperature contours.

\section{ERror ANALYSIS}

In order to estimate the statistical limitations of the MCC procedure, an effort was made to estimate the statistical significance of the cross-correlation maxima used to define the advective velocities in each window. An estmate of the appropriate degrees of freedom in each computational window was calculated by computing the autocorrelations in a series of windows for one of the images used. To represent the spatial variability over the image, all windows in the gradient image shown in Figure $2 a$ were used. The mean autocorrelation over all of these windows is shown here in Figure 3 as a threedimensional correlation surface. Unfortunately, the $x$ and $y$ zero-crossing scales are not the same, with the $y$ (north-south) zero-crossing scale at about $10 \mathrm{~km}(1 \mathrm{~km}$ per pixel) and the $x$ (east-west) scale at about $15 \mathrm{~km}$. Since in the computational method the statistics of $x$ and $y$ were not considered separately, we take an average of these two length scales to yield a length scale of $12.5 \mathrm{~km}$ for the mean, or isotropic, zerocrossing scale.

Within each cross-correlation calculation (template window) there are $22 \times 22$ pixels, or 484 points. To estimate how many of these points can be considered as independent, we divide the total points by the average autocorrelation length scale. This yields 39 degrees of freedom for each crosscorrelation calculation. At the $95 \%$ significance level any correlation over 0.304 is significant for $\mathbf{4 0}$ degrees of freedom; at the $99 \%$ level, correlations greater than 0.393 are significant, which coincides nicely with the arbitrarily chosen cutoff level of 0.4 [Ninnis et al., 1986] used to reject low cross-correlation values. While this is not a rigorous statistical test, it does suggest that for cross correlation above 0.4 , we are locating correlation maxima which are statistically well defined for the advanced very high resolution radiometer (AVHRR) data being used.

It is much more difficult to evaluate the influences of physical processes not included in the assumptions of the MCC method. As was suggested above, these processes are those other than horizontal advection which can change the SST. If we consider the local change of SST as being due to horizontal advection, vertical advection (upwelling and downwelling), local heating (or cooling), and mixing (both horizontal and vertical), we can make some estimate of the magnitudes of these processes over the time scales of interest. If we restrict 


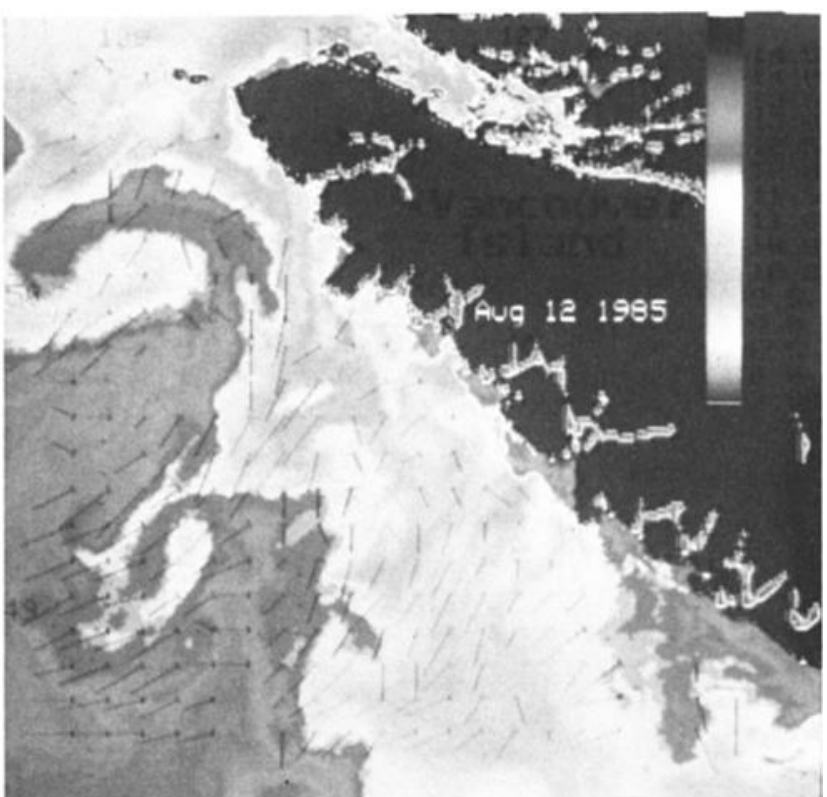

Fig. $5 a$

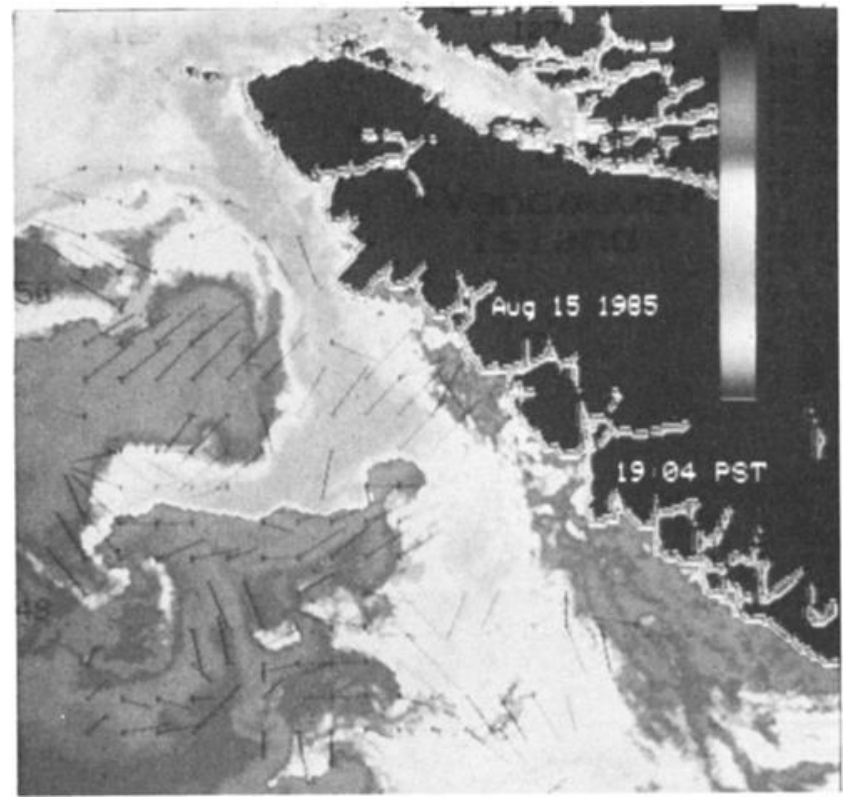

Fig. $5 c$

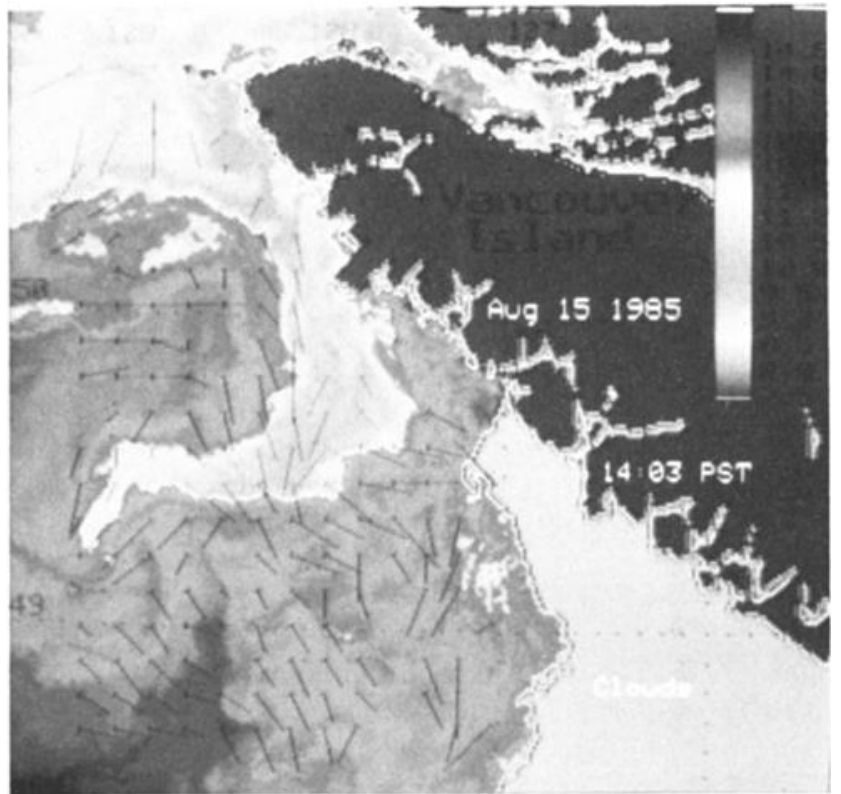

Fig. $5 b$

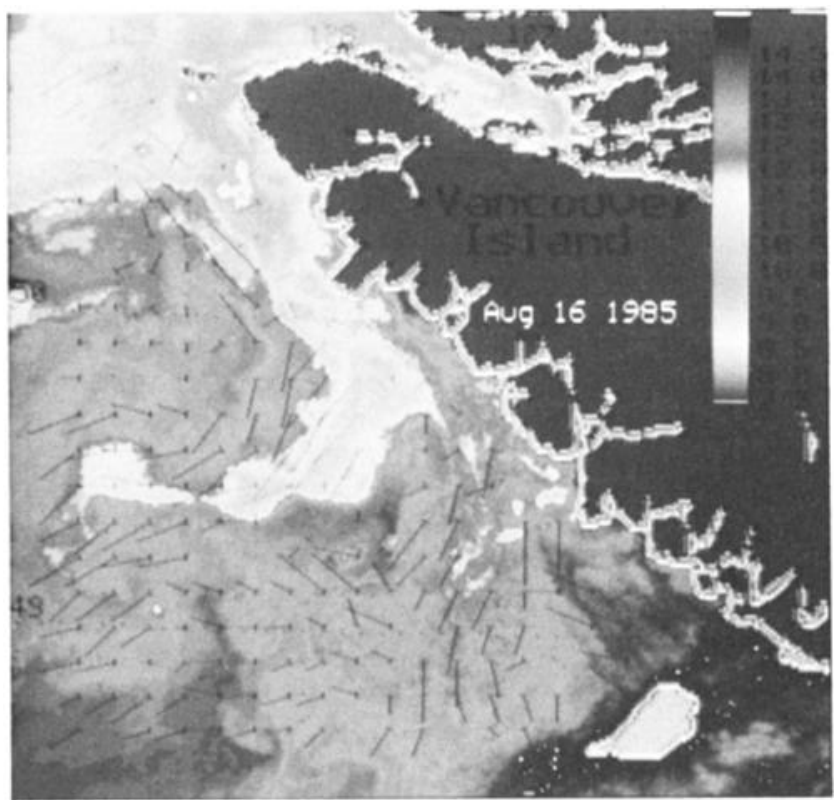

Fig. $5 d$

Fig. 5. Band 4 infrared AVHRR images with superimposed advective velocities for (a) 1435 PST August 12, 1985, with velocities from a pair of August 12 images at 1435 and 1829 PST; (b) 1403 PST August 15, 1985, with velocities from a pair of August 15 images at 1403 and 1904 PST; (c) 1904 PST August 15, 1985 with velocities from this image and an image from August 16 at 1354 PST; and (d) 1354 PST August 16, 1985, with velocities from a pair of August 16 images at 1354 and 1842 PST.

ourselves to changes over a maximum period of 24 hours (and we are generally concerned with significantly shorter intervals between images), it is unlikely that within this time interval the diffusive processes will act quickly enough to alter the SST pattern and thus affect the MCC calculation. Eliminating the mixing processes, we are left with the advective and heating and cooling mechanisms as the primary causes of changes in SST gradients. Since we are after the computation of horizon- tal advection we must then consider vertical advection and horizontally patchy heating and cooling as error sources which we cannot measure from the satellite data directly. Without additional in situ measurements we can only be aware of these possibly contaminating influences and try to account for them in the interpretation of the computed MCC velocities. As is mentioned later in the discussion of the calculated velocities, there are many cases where the velocities do 
not appear to reflect the expected advective field. As is suggested here, both vertical advection and small-scale heating and cooling events could be changing SST patterns which would produce cross-correlation changes not related to horizontal advection.

\section{IMAGE-Derived Surface Velocities}

The sequence of images, summarized in Table 1, separates into three groups: mid-June, late July, and mid-August. Sea surface temperature patterns in these three groups are distinctly different. The June images are dominated by a cold eddy off the mouth of Juan de Fuca Strait (Plate 1 and Figure 4) related to the presence of a topographic canyon, as was discussed by Freeland and Denman [1984]. A series of cold tongues all along the northwestern coast of Vancouver Island dominates the SST pattern in the July images (e.g., Plate 2). (Plates 1 and 2 are shown here in black and white. The color versions can be found in the separate color section in this issue.) These tongues form through baroclinic instability [Ikeda et al., 1984a, b] which converts energy from the highly sheared mean flow (southward surface current over a northward undercurrent) to mesoscale fluctuations which then develop into cyclonic eddies such as that clearly marked off Brooks Peninsula in Plate 2. A similar cold eddy was located at this position in the satellite images studied by Ikeda et al. [1984a] and in a study of in situ data by Thomson [1985]; both studies confirmed the existence of an eddy at this location and its generation by baroclinic instability. The last series of images from August 1985 documents the southward and seaward spread of a tongue of cold water (Figure 5), again off the northwest of Vancouver Island, replacing the eddy seen in the July images.

The first two of the three June images (Plates $1 a$ and $1 b$ ) clearly display the presence of a cold eddy just off the mouth of Juan de Fuca Strait. Cold water can also be seen in Plate $1 a$ coming out of the strait, suggesting a possible connection with the water in the eddy. It is more likely, however, that the cold water in the cyclonic eddy is instead an expression of local upwelling due to the eddy circulation [Freeland and Denman, 1984]. The June 17 image (Plate 1b) SST pattern is also dominated by the cyclonic eddy off the mouth of Juan de Fuca Strait. Again, a possible connection with cold water exiting from the strait is suggested by the surface temperature pattern. The third image in this sequence (Figure 4) is 24 hours later (Table 1) than the previous image on June 17. The cold cyclonic eddy is not as clearly expressed, and a significant amount of warmer water is present farther offshore. This is likely due to solar heating evidence of which is most clearly displayed by the water in Barkley Sound (see Figure 1 for location). On June 16 (Plate $1 a$ ) in a midday (1258 PST) satellite pass, this area is not significantly warmer than the adjacent coastal surface water. Thirteen hours later (0257 PST June 17), Plate $1 b$ shows this area somewhat warmer than the nearby coastal water; finally, 24 hours later, the June 18 image (Figure 4) shows the shallow water in Barkley Sound to be much warmer than the coastal water to the north or south.

Another interesting feature of these three images is the relative position of the cold water in Juan de Fuca Strait. In all three images the coldest temperatures are at the southwest limit of the strait, and the cold water turns sharply southward around Cape Flattery. The alongshore southward extent of this surface flow is not clear. In the images from June 16 and 17 (Plates $1 a$ and $1 b$ ) the slightly offshore tongue appears to stop at the southernmost latitude of the cyclonic eddy. The

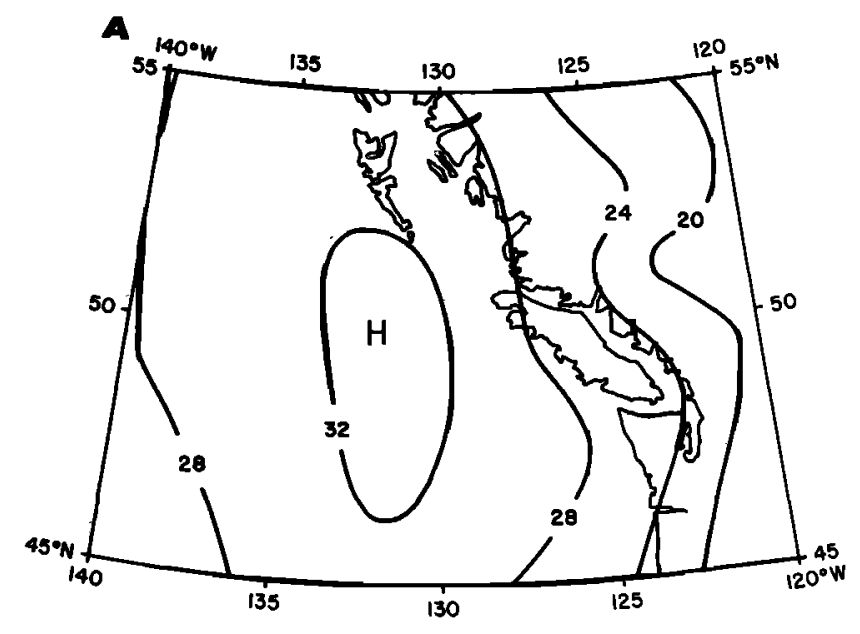

SEA LEVEL PRESSURE JUNE 16
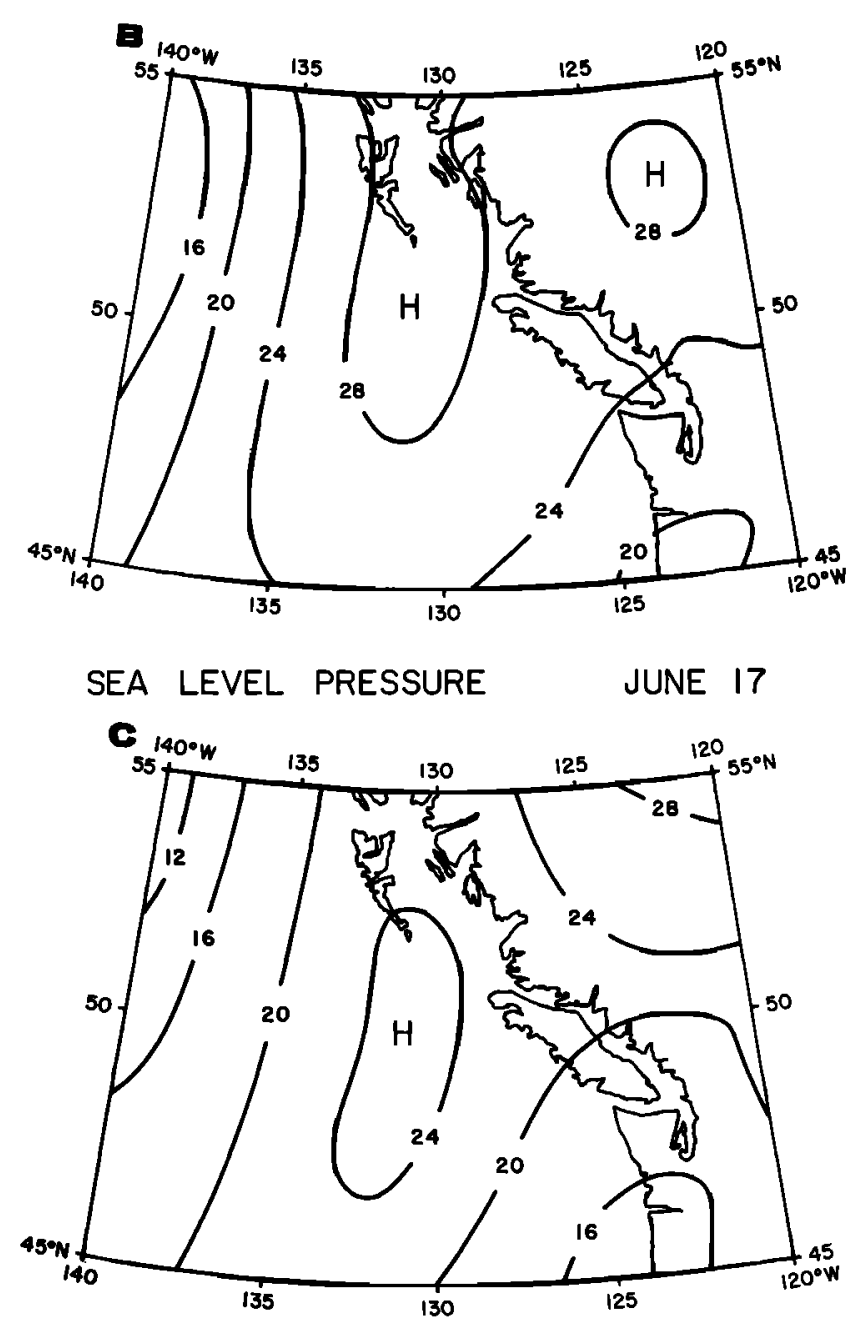

SEA LEVEL PRESSURE

JUNE 18

Fig 6. Sea level atmospheric pressure $(+1000 \mathrm{mbar})$ for (a) June 16 , (b) June 17, and (c) June 18, 1985. 


\section{NORA/NMFS PACIFIC ENVIRONMENTAL GROUP - MONTEREY, COASTAL UPWELLING INDICES, DAILY AND WE}

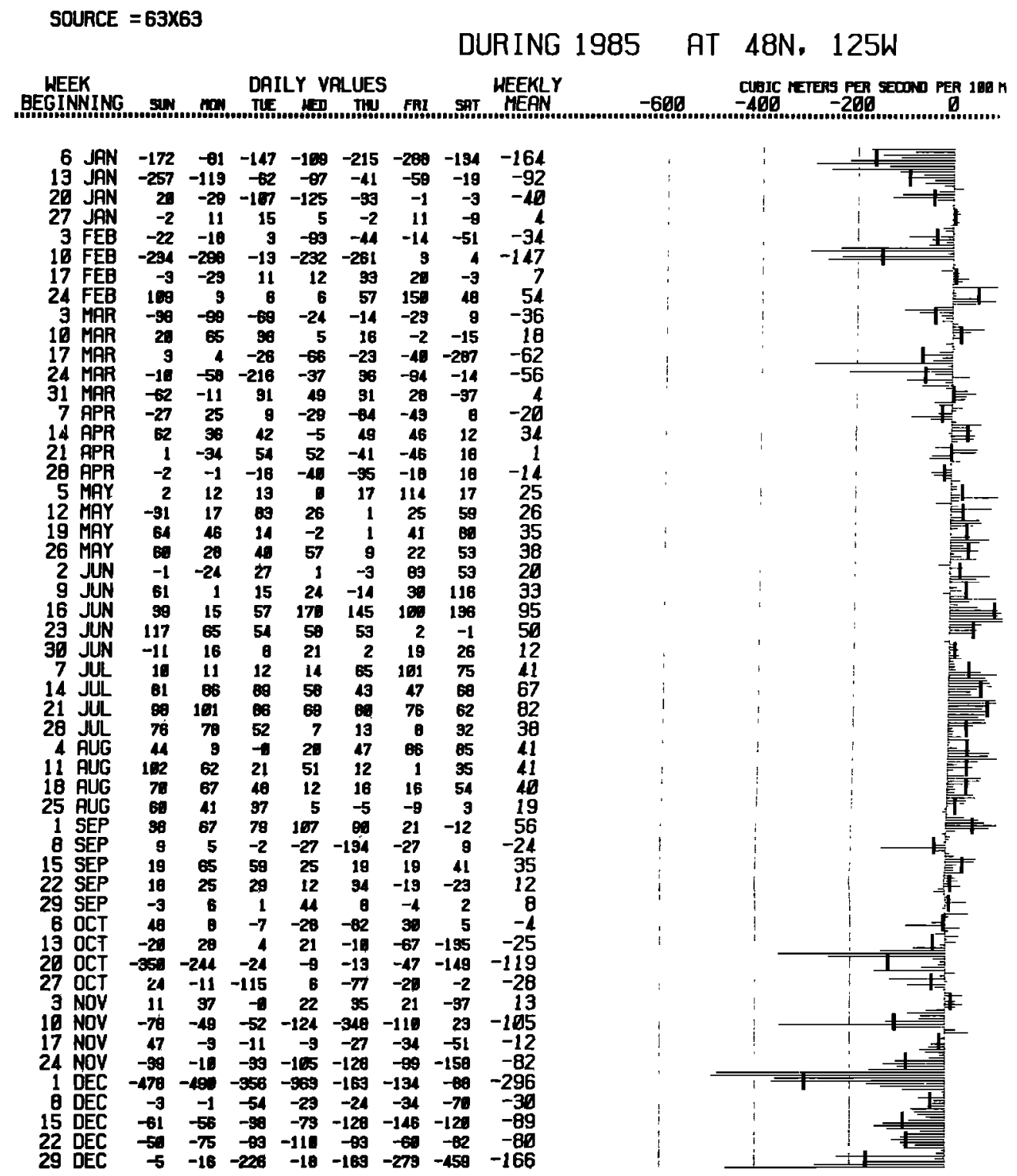

Fig. 7. Upwelling index [Bakun, 1973] at $48^{\circ} \mathrm{N}, 125^{\circ} \mathrm{W}$ for 1985 . Positive values indicate upwelling in response to northwesterly winds; $100 \mathrm{~m}$ refers to $100 \mathrm{~m}$ of coastline.

June 18 image (Figure 4) shows the cold water from Juan de Fuca as a much narrower tongue extending southward far beyond this earlier limit. In all three images the surface temperatures closest to the coast of Washington state are generally warmer with isolated pockets of very warm water. The cold water discharged from Juan de Fuca also extends northward along the coast of Vancouver Island as the significant density component (salinity rather than temperature dominates the density) of the Vancouver Coastal Current (R. Thomson, personal communication, 1986). The connection between Juan de Fuca water and the cold coastal water off Vancouver Island appears to be broken by the warm surface waters (Figure 4) in Barkley Sound, which, as we have discussed, are likely due to local solar heating in the shallow coastal water. The important freshwater contribution that the Juan de Fuca water makes to the coastal current cannot be seen in the SST images. It must also be remembered, however, that cold coastal water during the summer off Vancouver Island may also be due to wind-driven upwelling [Ikeda and Emery, 1984], which, as was mentioned in the error analysis, may have also had an effect on the MCC velocities.

Surface advective velocities were calculated, using the MCC technique, between the SST gradients from pairs of the three June images. Thus two sets of vectors were calculated; one between June 16 and 17 and the second between June 17 and 18. The advective velocities represent the temporal changes over first a period of 12 hours and second a period of 24 hours. As a rule, we will display the resultant velocity vectors 


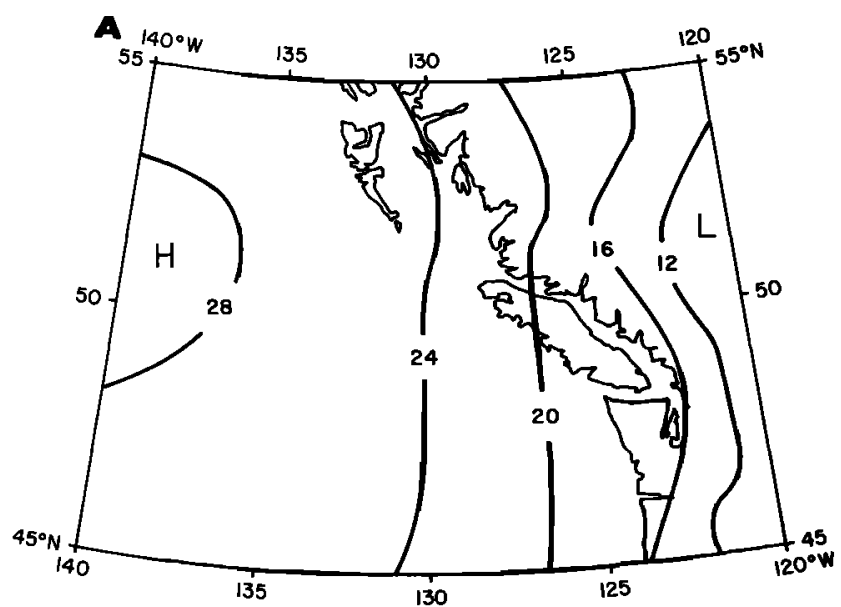

SEA LEVEL PRESSURE JULY 26

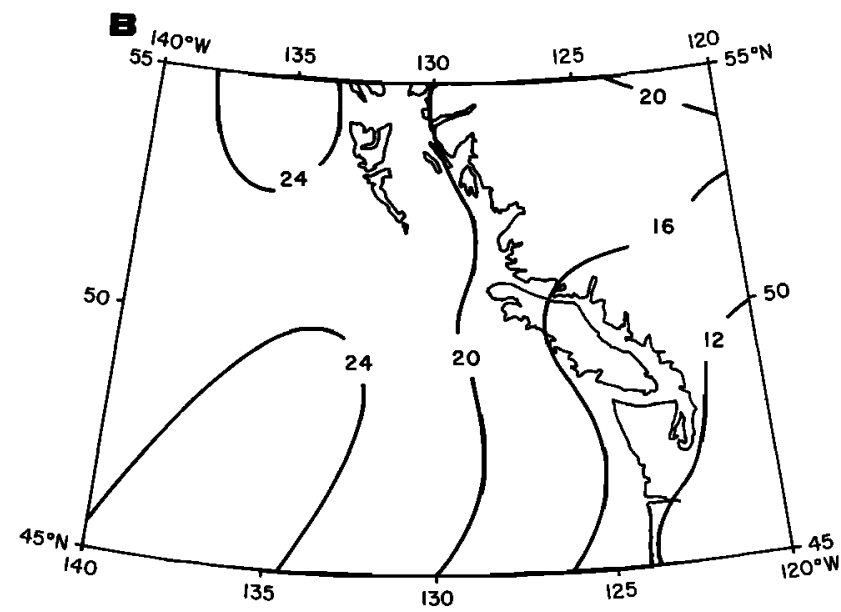

SEA LEVEL PRESSURE

JULY 28

Fig. 8. Sea level atmospheric pressure $(+1000$ mbar) for (a) July 26 and $(b)$ July $28,1985$.

on the temperature pattern of the first image of the pair. Thus the SST images of the first 2 days (Plates $1 a$ and $1 b$ ) also contain velocity vectors, while the third image (Figure 4) displays only the temperature pattern.

Both sets of velocity vectors for this sequence of images do not appear to relate directly to currents flowing along SST gradients. Consistent with the southward directed summer sur[ace current [Ikeda et al., 1984b], many of the computed vectors point south. The velocities parallel to the coast are much stronger in the second set of vectors, suggesting a stronger mean current. This may be in response to the stronger winds off Vancouver Island as revealed in the daily 1200 UT sea level atmospheric pressure patterns for June 16-18 (Figures $6 a-6 c$ ). The weaker and offshore directed geostrophic winds on June 17-18 may have led to a stronger expression of the southward surface current between June 17 and 18. It is also interesting to note that the alongshore winds, on June 16 , result in a relatively large value of the Bakun [1973] upwelling index as presented here in Figure 7 for a location just off the southern end of Vancouver Island. The upwelling event in mid-June 1985 is one of the strongest upwelling events in 1985 .

A combination of wind-driven and geostrophic surface flows is represented by the first set of vectors (Plate 1a). Over the cold eddy, the June 16-17 advective velocities agree generally with the circulation of this cyclonic feature. Away from the cold eddy, the June 16-17 velocities (Plate $1 a$ ) are less spatially coherent, which may reflect the sharp increase in wind forcing indicated by the upwelling index on this date. The incoherent nature of the offshore advective velocities may be due to the transient nature of these currents which have not yet reached an equilibrium with the stronger wind forcing. The northerly velocities at the southern edge of Plate $1 a$ cannot be explained by an increase in upwelling favorable winds and instead appear to represent the northward intrusion of warm surface water, as can be seen by comparing the SST patterns for June 16 and 17 (Plates $1 a$ and $1 b$.) This northward extension of SST cannot be explained by any advective mechanism and may be the result of rapid surface warming taking place under clear sky conditions.

The subsequent set of image advective velocities (June 17-18) no longer contains a substantial number of northward velocities. Instead, the currents nearest the coast are stronger and southeastward, consistent with both the mean and winddriven flows. Velocity vectors still deviate somewhat from the southeastward direction in the vicinity of the cyclonic eddy, revealing its continued presence. Farther offshore the imagederived velocities (Plate $1 b$ ) turn westward in agreement with the geostrophic wind patterns in Figures $6 b$ and $6 c$; a delay in the response of the surface advective field to changes in the wind forcing, is suggested by the differences between the June 16-17 and June 17-18 velocities. These short-term changes emphasize the need for and the benefit of being able to resolve the rapid space-time variations in the velocity field and its response to external forcing.

Four images were available for the latter part of July (Table 1), two from July 26 (12 hours apart) and two from July 28 (5 hours apart). We present here only the first two images from each pair together with the velocity vectors computed for the pair. All of the July images (e.g., Plate $2 a$ for July 26) clearly displayed a cold eddy off Brooks Peninsula. This is the northernmost cyclonic eddy discussed by Ikeda et al. [1984a] and observed in situ by Thomson [1985]. The water in this eddy appears to be colder than the coastal water farther south, and the temperature pattern (particularly that in Plate $2 a$ ) suggests a possible connection to cold temperatures off the northern tip of Vancouver Island (on both the eastern and western sides). Streamers off of this cold eddy (Plate $2 b$ ) clearly indicate the cyclonic vorticity associated with it. It is surprising how well the surface temperature pattern in the interior of this eddy displays its cyclonic character.

The two sets of independent surface advective velocity vectors computed for each pair of July images, while being similar in overall pattern (average current is directed southward), are 


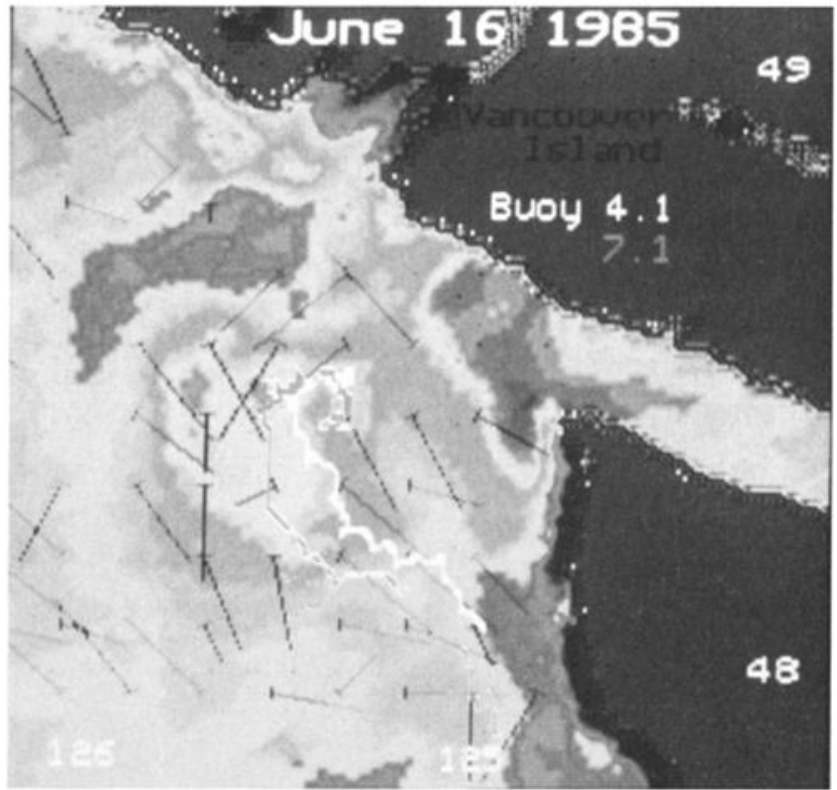

Plate 3. Enlargement of the southwest corner of image from June 16 with advective velocities from June $16-17$ and trajectories from surface drifters 4.1 and 7.1. (The color version of this figure can be found in the separate color section in this issue.)

in detail quite different. In the July 28 image (Plate $2 b$ ) the velocity vectors, superimposed on the cold tongues, appear to be more related to the temperature pattern than those for July 26 (Plate 2a). Over the cyclonic eddy the July 28 vectors appear to rotate around the cold feature (Plate $2 b$ ), while the July 26 vectors suggest instead an offshore displacement of the eddy (Plate $2 a$ ). This is perhaps a consequence of the longer separation for the first image pair (12 hours) compared to the shorter ( 5 hours) separation for the second pair. As was stated earlier, the advective assumption is more likely met by the shorter image separation, even for the larger-scale (geostrophic eddy scale) rotational motion.

It is interesting that the velocities from the second image pair (Plate $2 b$ ) also show northward directed velocities adjacent to the coast just south of Brooks Peninsula. This is likely an expression of the Vancouver Island Coastal Current which farther south is masked by warmer water likely due to local solar heating. Elsewhere, both sets of velocity vectors show a generally southward current consistent with the accepted mean surface current pattern. The atmospheric pressure patterns for this period (Figures $8 a$ and $8 b$ ) exhibit near-normal southward geostrophic winds also expressed by the positive values of the upwelling index for this period (Figure 7).

A total of eight relatively clear infrared images were available for the middle of August (Table 1). Again, we present only the first of each image pair except for the second image on August 15, which is the first image in a subsequent pair (August 15 and August 16). Temporal separations (Table 1) range from only 4 hours (August 12) to 19 hours between the second August 15 image and that from August 16. The SST patterns from August 12 to August 16 are dominated by a tongue of cold water off Brooks Peninsula that replaces the cold eddy seen in July. A weak expression of this eddy can still be seen in the August 12 image (Figure $5 a$ ) displaced to the south relative to the July 18 representation of the eddy (Plate
$2 b$ ). It appears that the eddy has weakened and combined with the neighboring cold tongue just to the south. This tongue now extends a bit farther offshore (Figure $5 a$ ) and terminates in the $\mathrm{T}$-shaped expression of matched counterrotating (or dipole) eddies [Ikeda et al., 1984a]. In the next image, from August 15 (Figure $5 b$ ), the tongue no longer terminates in the $T$ shape. The cold-core expression of the cyclonic eddy is also absent, and the cold tongue is more sharply defined by the intrusion of warmer surface water to its south. A central core of colder water runs from the northern tip of Vancouver Island southwrd through the center of the cold tongue. It may be that the cyclonic eddy has separated from the coastal flow as was observed and modeled by $I$ keda et al. $[1984 a, b]$; after separation from the sustaining cold coastal water, the surface expression of the cold eddy is quickly erased by solar insolation.

Subsequent images (Figures $5 c$ and $5 d$ ) show short-term (both images are within 30 hours of the first Aug. 15 image) changes in the cold tongue and the surrounding thermal structure. It should be noted that all of the August images are from the afternoon and early evening, thus reducing the likelihood that diurnal heating and cooling will substantially alter the surface temperature patterns. Instead, SST changes are more likely due to variations in the surface currents responding to both geostrophic and wind-driven current fluctuations. In all of these August images the coldest water is found off the northwest tip of Vancouver Island and in Figure $5 c$ appears to advect southward and then offshore in the cold tongue.

Advective velocities computed for the first August image pair (August 12, Figure $5 a$ ) are spatially very coherent showing a southward current which turns sharply westward. The wind-driven nature of these current vectors is indicated by their lack of agreement with the SST pattern. The velocities run across most of the dominant temperature gradient features. The pattern is, however, very consistent with the atmospheric pressure distribution for this day. This sea-level pressure pattern yields much stronger winds in this area than were seen in earlier (Figure 6) and subsequent pressure patterns. Winds from August 15 are consistent in direction with those from August 12 but are much weaker. It is therefore no surprise that the surface advective velocities for the image pair of August 15 are not as spatially coherent (Figure $5 b$ ) as those for August 12. The generally southward velocities are consistent with the wind pattern but the onshore (southeastward) velocities, in the southern third of the image, cannot be explained by the geostrophic wind, which still turns west at these latitudes. One possible explanation is seen in the eastward intrusion of the warm water tongue just south of $50^{\circ} \mathrm{N}$. Whether advective, due to upwelling, or due to solar heating, the MCC technique interprets these changes as purely advective, giving the corresponding velocity field with its eastward currents.

Velocities for the remaining two image pairs (Figures $5 c$ and $5 d$ ) are even less spatially coherent. Much stronger southward, alongshore velocities between August 15 and August 16 (Figure 5c) may be related to the shift in the geostrophic wind between August 15 and August 16. That these stronger alongshore velocities are more apparent in the image pair between August 15 and 16 is likely due to the fact that the time interval between these images includes a night and a morning, while the interval between the images of the second pair is all on a single afternoon (Table 1). During the night and early morning the solar heating is much reduced, and the colder coastal 


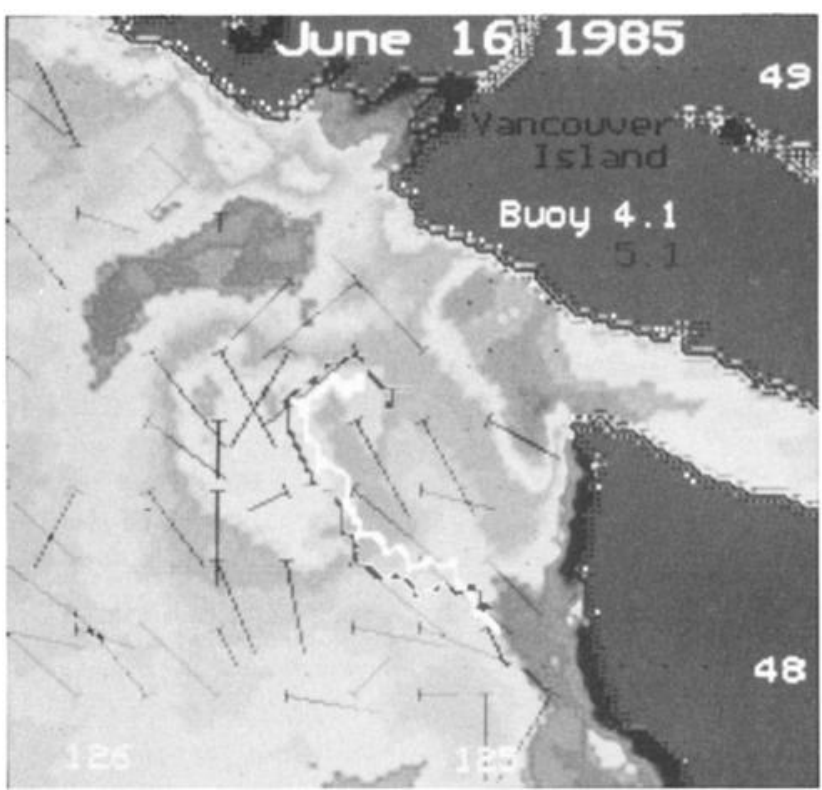

Fig. $9 a$

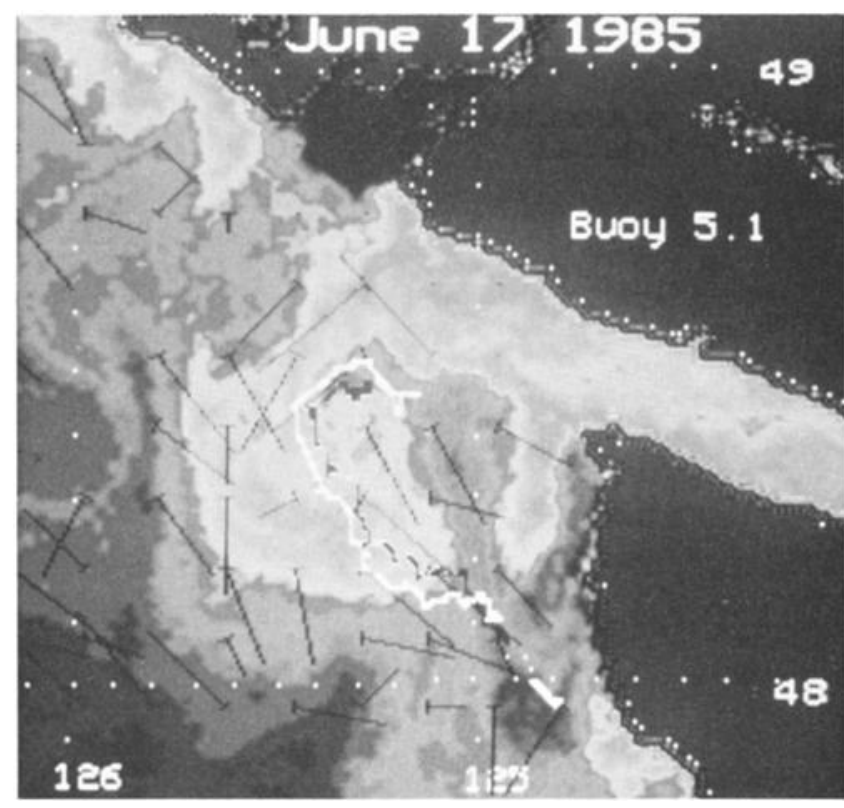

Fig. $9 b$

Fig. 9. Enlargements of the southwest corners of images from (a) June 17 with advective velocities from June 16-17 and trajectories from surface drifters 4.1 and 5.1, and (b) June 17 with advective velocities from June 16-17 and trajectories from surface drifters 4.1 and 5.1.

water, related to the southward current structure, can dominate (Figure $5 c$ ). In the afternoon sequence (Figure $5 d$ ), solar heating can more strongly influence the surface temperature (under the observed relatively cloud free conditions) erasing the expression of the underlying currents. Thus the velocities in the southern half of the second image pair (Figure $5 d$ ) indicate changes in the warm and cold tongues which may be due to advection, heating and cooling, or upwelling.

\section{Comparisons Between Advective Velocities AND BUOY TRAJECTORIES}

As is discussed in the data section and summarized in Table 2 , a series of shallow-drogued drifters were tracked in the area of the cyclonic eddy off the mouth of Juan de Fuca Strait in mid-June. To demonstrate the correspondence between these buoy trajectories and the surface advective velocities, we have plotted both on the images from June 16 and 17 zoomed in around the cold eddy (Plate 3 and Figure 9). (Plate 3 is shown here in black and white. The color version can be found in the separate color section in the issue.) Since the buoys had very similar trajectories over this relatively short period, and because of the strong similarity between the trajectories and the advective velocities, we could not plot all of the trajectories together with the velocity vectors (the trajectories overwrote the vectors). Instead we have selected some representative buoy trajectories and plotted them with the corresponding advective velocity vectors. In Plate 3, long trajectories from buoys 4.1 and 7.1 (Table 2) are plotted along with the advective velocities from June 16-17 on the image from June 16. The agreement between the buoy tracks, the advective velocities, and the SST pattern is clearly displayed. The buoys appear to move around the warm intrusion on the eastern side of the cold eddy and then move predominantly south, turning eastward at the edge of the eddy. These paths are very consistent with most of the advective velocities from the SST gradient images.

Superimposed on the June 17 image in Figure $9 a$ we show the tracks of buoys 4.1 and 5.1 along with the advective velocities from June 16-17. Again, the agreement between image derived velocities and buoy trajectories is excellent. The buoy tracks rotate cyclonically about the eastern edge of the eddy and then turn to the south before turning east at the edge of the eddy. All of these turns are consistent with most of the advective velocities.

Finally the same two buoy trajectories (buoys 4.1 and 5.1) are superimposed on the infrared image from June 17 (Figure $9 b$ ) along with the June 16-17 advective velocities. Both buoy tracks and velocity vectors appear to rotate cyclonically about the warm patch of water on the eastern side of the cold eddy. Strong southeastward motion, near the southern edge of the eddy, is indicated by both the buoy trajectories and the advective velocities. The stronger velocities are a response to the strong geostrophic wind from June 16 (Figure $6 a$ ).

\section{Comparison with Geostrophic Currents}

A set of shallow CTD casts collected during the buoy tracking experiment was used to define the near-surface geostrophic flow by mapping the 15/110-dbar dynamic topography. We present this dynamic height map in Plate 4 together with the June 16-17 advective velocities superimposed on the satellite image from June 17. The circulation of the cyclonic eddy is clearly displayed by the objectively analyzed [Freeland and Gould, 1976] 15/110-dbar dynamic topography (Plate 4); the eddy is centered at $43.3^{\circ} \mathrm{N}$ and $125.4^{\circ} \mathrm{W}$. (Plate 4 is shown 


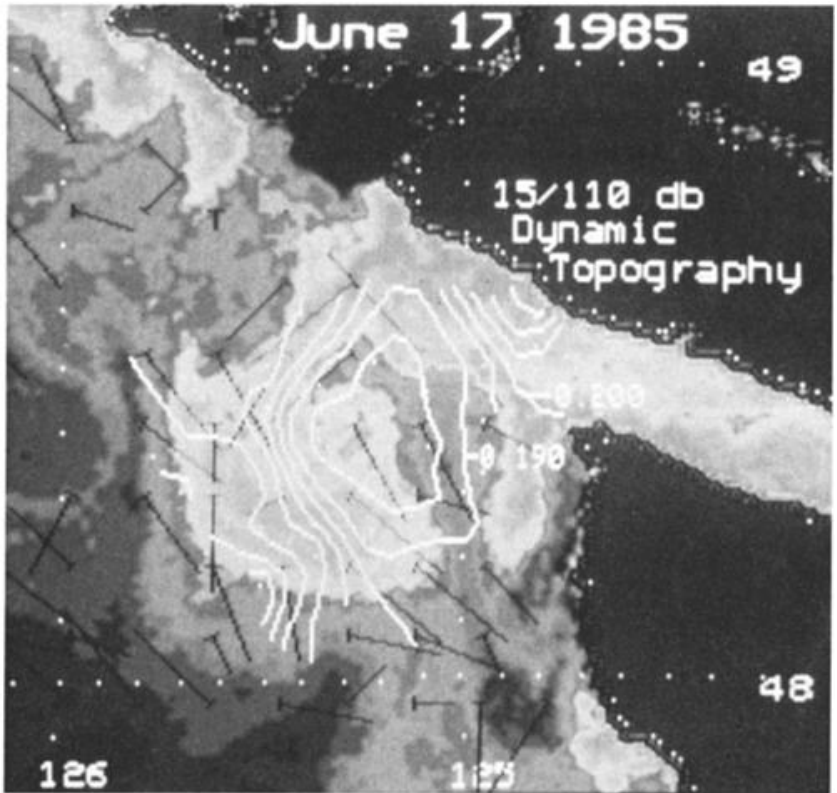

Plate 4. Enlargements of the southeast corner of the June 17 image with June 16-17 advective velocities and contours of 15/110dbar dynamic height (contour interval $=0.005 \mathrm{dyn} m$ ) from the CTD casts (station positions are indicated by white dots). (The color version of this figure can be found in the separate color section in this issue.)

here in black and white. The color version can be found in the separate color section in this issue.) The contours in Plate 4 clearly indicate the geopotential gradient associated with this eddy. The agreement between these two independent realizations of the surface current structure is demonstrated by the similarities in the shapes of the contours and the advective velocity vectors. In interpreting this comparison it should be cautioned that the CTD stations were collected over a 10-day period (June 9 to June 19), while the image advective velocities only pertain to advection occurring over the 14-hour period between the June 16 and June 17 images (Table 1). Thus the agreement between the longer-term geostrophic flow and the surface advective velocities reflects the dominance of the surface flow by the geostrophic flow of the cyclonic eddy. It is unlikely that similar comparisons for areas of the image far removed from this eddy would have been as favorable. This is particularly true of the southwest portion of the study region where, as has been discussed, the northward directed image velocities (Plate 1a) are probably expressions of local surface heating rather than advection. The southeastward directed advective velocities, in the southeast quadrant of the eddy, conflict with the geostrophic flow and likely reflect wind-driven rather than geostrophic surface currents.

Another valuable piece of information provided by the CTD data is shown by the sample temperature $(T)$ and salinity $(S)$ profiles in Figure 10. The stippled band between 5 and $10 \mathrm{~m}$ corresponds to the drogue depths of the drifting buoys whose trajectories have been discussed above. The $T-S$ stratification reveals that the drogue elements are all within the upper "mixed layer," whose motion is best represented by the image advective velocities. The presence of the drogues in this shallow upper layer helps to explain the excellent correspon- dence between the drifter tracks and the advective velocities. It should be recognized here that for the nearshore region, salinity is often the dominant variable in dictating the density structure. This is particularly true in early summer when the freshwater discharge of the Fraser River reaches a maximum [Royer and Emery, 1982].

\section{SUMmaRY}

Sequential NOAA satellite AVHRR images of the British Columbia coastal ocean have been used to compute spatial SST gradients from the $11-\mu \mathrm{m}$ infrared channel. Successive SST gradient images were two-dimensionally lag correlated in coincident $32 \times 32$ search and $22 \times 22$ template windows. The position of maximum correlation in each window was taken as the end point of an advective surface velocity vector, starting from the appropriate window center for the time period between images. Resulting velocities computed for eight images from the summer of 1985 appear consistent with the geostrophically balanced surface currents perturbed by local wind events. Image-derived advective velocities represent a combination of both geostrophic mean and shorter-term wind-driven surface currents. Strong, upwelling favorable winds appear to dominate the advective velocities, but a phase lag of about a day is suggested by comparing the sea level atmospheric pressure-driven upwelling index and the corresponding image advective velocities. During periods of weaker winds the advective velocities appear more geostrophic in character, as is partially suggested by the SST patterns themselves. Unable to estimate motion other than translational surface advection, the method fails to accurately represent local upwelling and surface heating events. In the vicinity of a vigorous, coastal cyclonic eddy the image advective velocities compare well in both speed and direction with coincident measures of geostrophic current and Lagrangian trajectories.

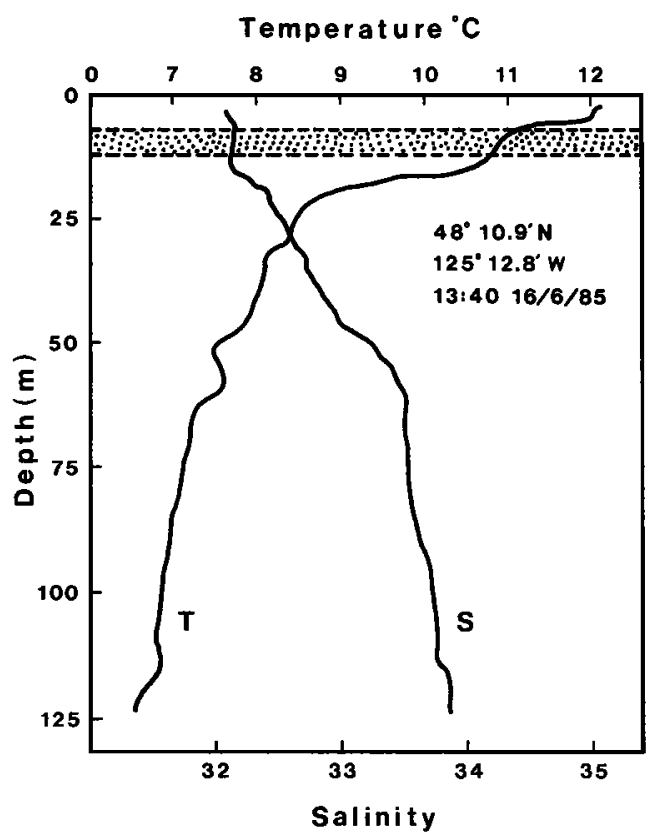

Fig. 10. Temperature $(T)$ and salinity $(S)$ profiles at the deployment position of drifter $7\left(48^{\circ} 10.9^{\prime} \mathrm{N}, 125^{\circ} 12.8^{\prime} \mathrm{W}\right)$. The shaded band indicates the depth of the drogues. 
This agreement confirms the representative character of the advective velocities in a region dominated by geostrophic currents.

Acknowledgments. This research was supported by a variety of grants to W. J. Emery by the Canadian Natural Engineering Research Council; this support is gratefully acknowledged. Many people contributed to the collection and analysis of the satellite imagery; our appreciation goes to $P$. Nowlan for operating the receiving station and to D. Laplante and W. Meyers for their dedication to the development of useful software. B. Mueller initially processed all of the summer images. Howard Freeland processed most of the CTD data and contributed to the interpretation of these data.

\section{REFERENCES}

Bakun, A., Coastal upwelling indices, west coast of North America, 1946-71, NOAA Tech. Rep., NMFS SSRF 671, 103 pp., 1973.

Bernstein, R. L., and D. B. Chelton, Large-scale sea surface temperature variability from satellite and shipboard measurements, $J$. Geophys. Res., 90, 11,619-11,630, 1985.

Emery, W. J., and M. Ikeda, A comparison of geometric correction methods for AVHRR imagery, Can. J. Remote Sens., I0, 46-56, 1984.

Freeland, H. J., and K. L. Denman, A topographically controlled upwelling center off southem Vancouver Island, J, Mar, Res., 42, 1069-1093, 1984.

Freeland, H. J., and W. J. Gould, Objective analysis of mesoscale ocean circulation features, Deep Sea Res., 23, 915-923, 1976.

Ikeda, M., and W. J. Emery, An upwelling event observed in satellite images over the continental shell off Vancouver Island, J. Mar. Res., 42, 303-317, 1984.

Ikeda, M., L. A. Mysak, and W. J. Emery, Observation and modelling of satellite-sensed meanders and eddies off Vancouver Island, $J$. Phys. Oceanogr., 14, 3-21, 1984a.

Ikeda, M., W. J. Emery, and L. A. Mysak, Seasonal variability of meanders in the California Current system off Vancouver Island, $J$. Geophys. Res., 89, 3487-3505, 1984b.

Kelly, K. A., Swirls and plumes or applicatıon of statistical methods to satellite-derived sea surface temperatures, Ph.D. thesis, SIO Ref 83-15, CODE Tech. Rep., 18, 210 pp., Scrıpps Inst. of Oceanogr., La Jolla, Calif., 1983.
Kelly, K. A., The influence of winds and topography on the sea surface temperature patterns over the northern California slope, $J$. Geophys. Res., 90, 11,783-11,798, 1985.

La Violette, P. E., The advection of submesoscale thermal features in the Alboran Sea Gyre, J. Phys. Oceanogr., 14, 450-505, 1984.

Leese, J. A., C. S. Novak, and B. B. Clarke, An automated technique for obtaining cloud motion from geosynchronous satellite data using cross correlation, $J$. Appl. Meteorol., IO, 110-132, 1971.

McGillem, C. D., and M. Svedlow, Image registration error variance as a measure of overlay quality, IEEE Trans. Geosci. Electron. GE-14, 44-49, 1977.

McGillem, C. D., and M. Svedlow, Optimum filter for minimization of Image registration error variance, IEEE Trans. Geosci. Electron., GE-15, 257-259, 1978.

Ninnis, R. M., W. J. Emery, and M. J. Collins, Automated extraction of pack ice motion from AVHRR imagery, J. Geophys. Res., 91 10,725-10,734, 1986.

Royer, L., and W. J. Emery, Computer simulations of the Fraser River Plume, J. Mar. Res., 43, 289-306, 1982.

Svedlow, M., C. D. McGillem, and P. E. Anuta, Image registration: Similarity measure and preprocessing method comparisons, IEEE Trans. Aerosp. Electron. Syst., AES-14, 141-149, 1978.

Thomson, R. E., A cyclonic eddy over the continental margin of Vancouver lsland: Evidence for baroclinic instability, J, Phys. Oceanogr., 14, 1236-1646, 1985.

Van Woert, M., The subtropical front: Satellite observations during FRONTS 80, J. Geophys. Res., 87, 9523-9536, 1982.

Vastano, A. C., and S. E. Borders, Sea surface motion over an anticyclonic eddy on the Oyashio front, Remote Sens. Environ., 16, $87-90,1984$.

Vastano, A. C., and R. O. Reid, Sea surface topography estimation with infrared satellite imagery, J. Atmos. Technol., 2, 393-400, 1985.

M J. Collins and A. C. Thomas, Department of Oceanography, University of British Columbia, Vancouver, British Columbia, Canada V6T $1 \mathrm{~W} 5$.

W. R. Crawford and D. L. Mackas, Institute of Ocean Sciences, P.O. Box 6000, Sidney, British Columbia, Canada V8L 4B2.

W. J. Emery, National Center for Atmospheric Research, P.O. Box 3000, Boulder, CO 80307.

(Received May 2, 1986; accepted June 12, 1986.) 


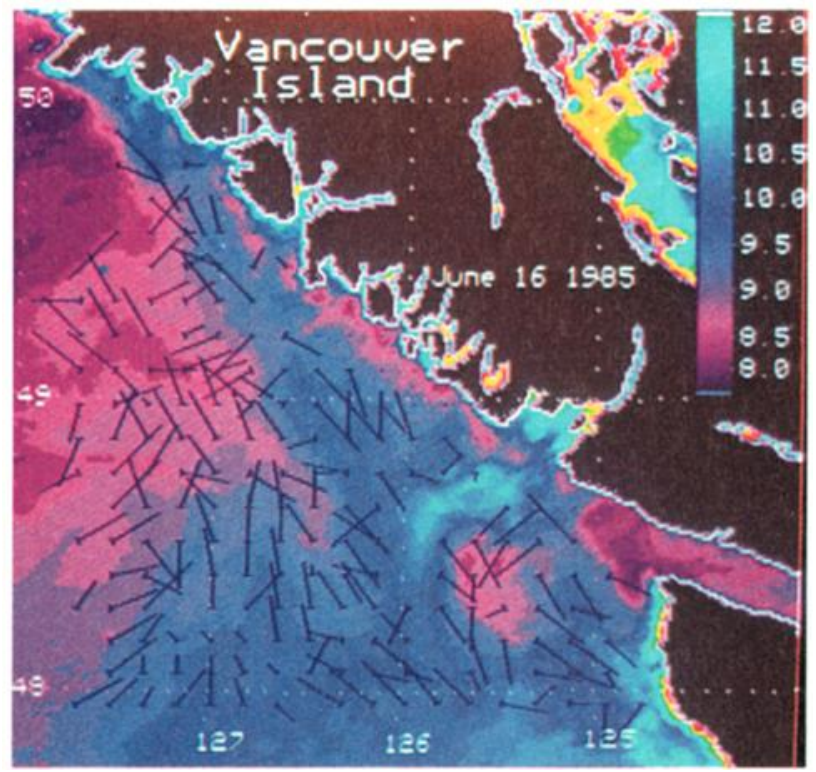

Plate $1 a$

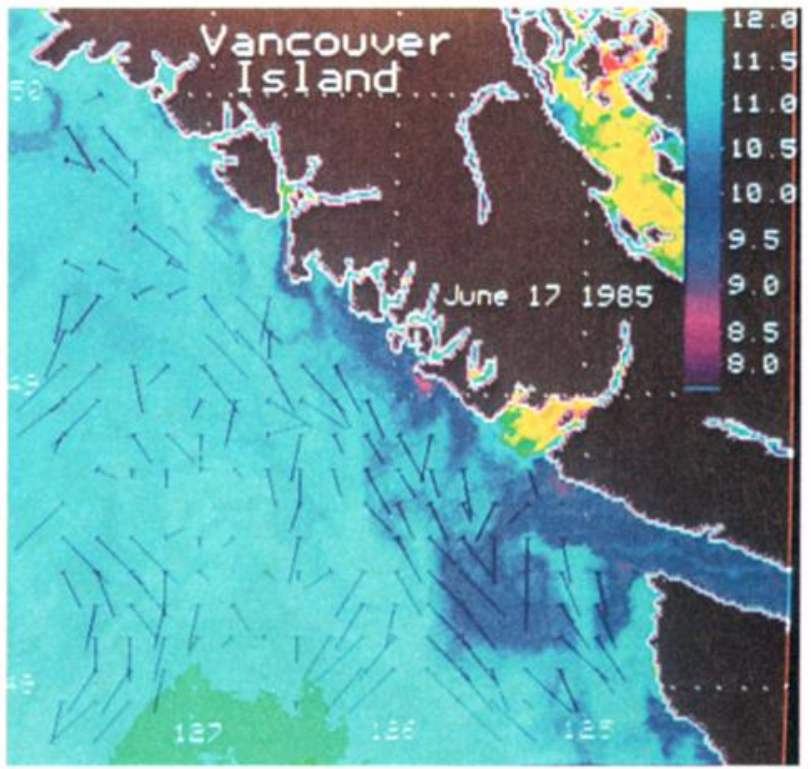

Plate $1 b$

Plate 1 [Emery et al.]. Band 4 infrared AVHRR images with superimposed advective surface velocities for (a) 1208 PST June 16, 1985, with velocities for the June 16-17 image pair and (b) 0257 PST June 17, 1985, with velocities for the June 17-18 image pair.

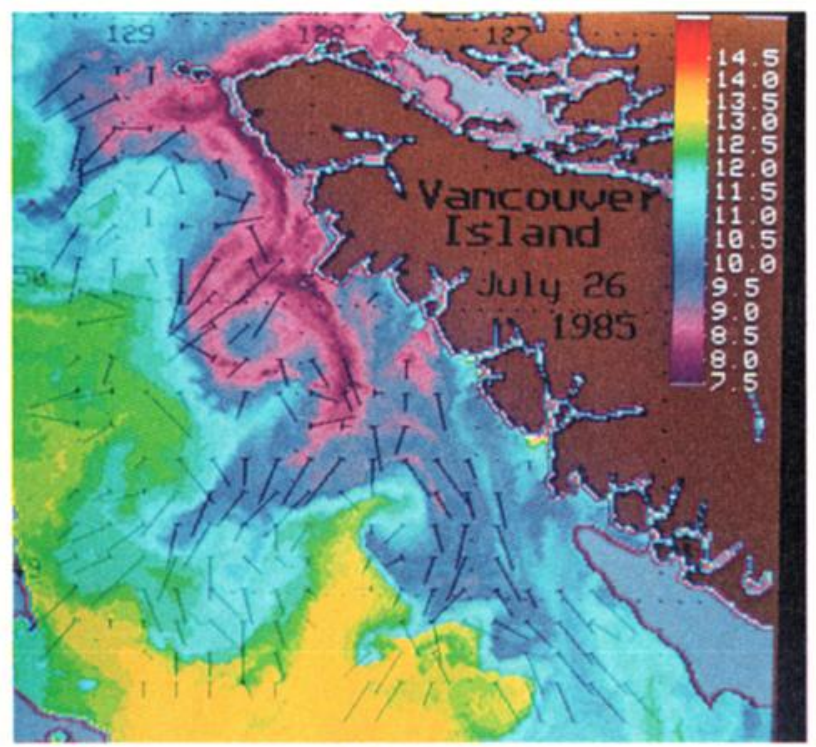

Plate $2 a$

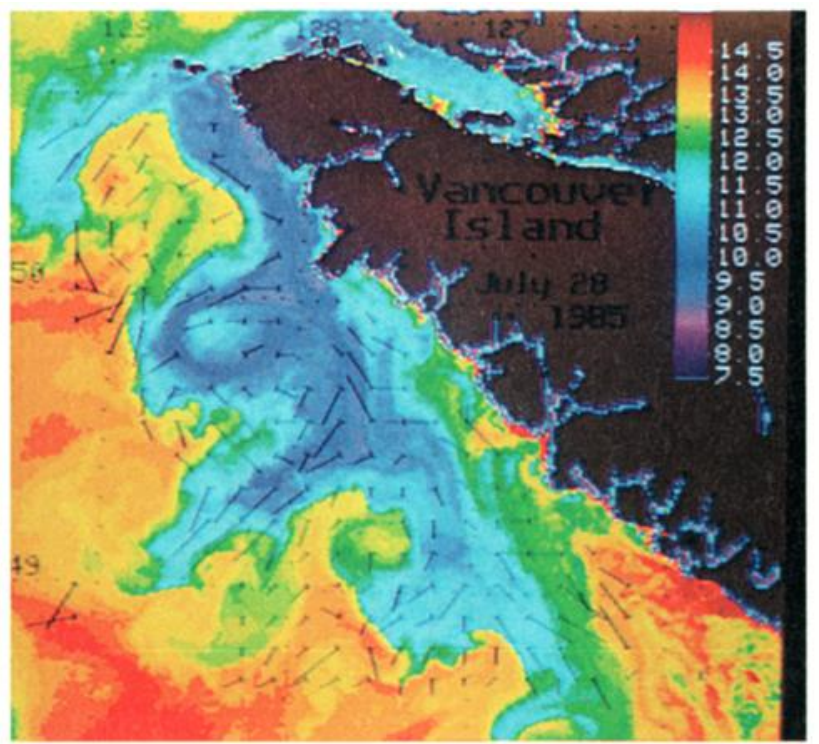

Plate $2 b$

Plate 2 [Emery et al.]. Band 4 infrared AVHRR images with superimposed advective surface velocities for $(a) 0811$ PST July 26, 1985, with velocities for a pair of July 26 images at 0811 and 1937 PST and (b) 1353 PST July 28, 1985, with velocities for a pair of July 28 images at 1353 and 1854 PST. 


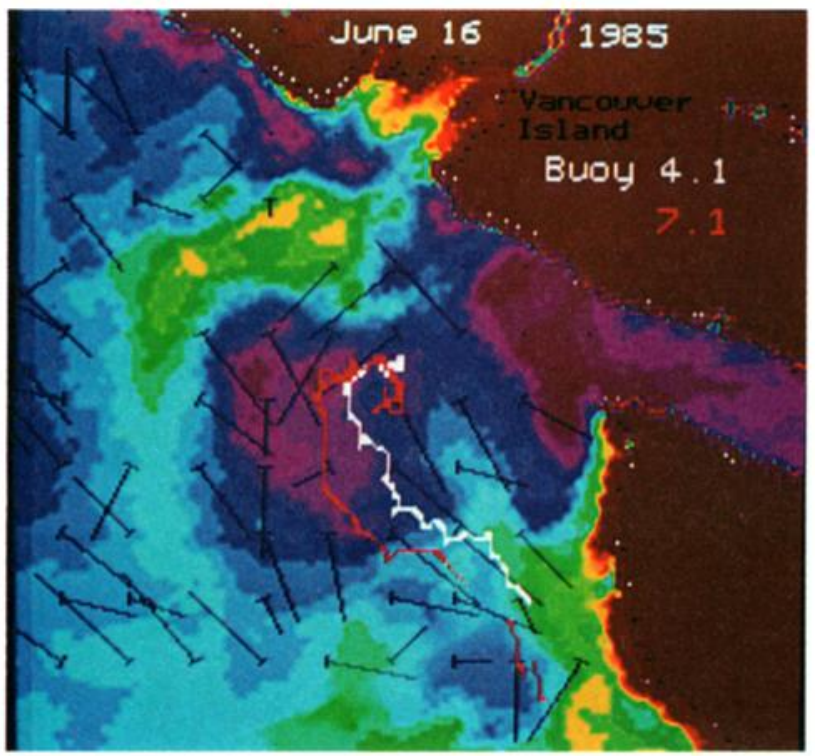

Plate 3 [Emery et al.]. Enlargements of the southwest corner of image from June 16 with advective velocities from June $16-17$ and trajectories from surface drifters 4.1 and 7.1.

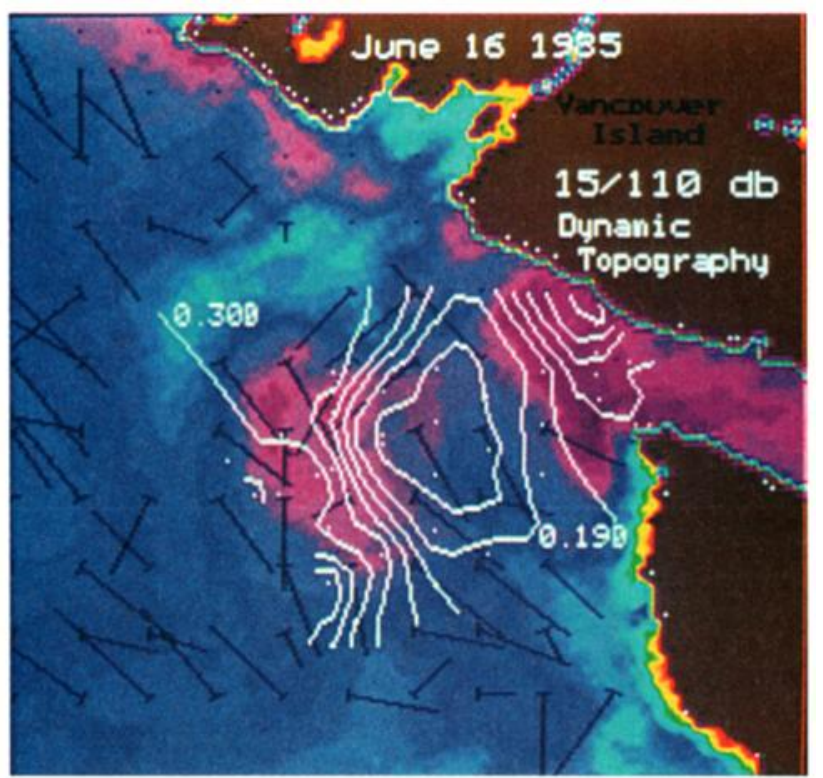

Plate 4 [Emery et al.]. Enlargements of the southeast corner of the June 17 image with June 16-17 advective velocities and contours of 15/110-dbar dynamic height (contour interval $=0.005 \mathrm{dyn} \mathrm{m}$ ) from the CTD casts (station positions are indicated by white dots). 